\title{
On the outside looking in: rethinking the molecular mechanism of 1,3- dipolar cycloadditions from the perspective of bonding evolution theory. The reaction between cyclic nitrones and ethyl acrylate
}

\author{
A. I. Adjieufack ${ }^{a}$, I. M. Ndassa ${ }^{b} *$, I. Patouossa ${ }^{a}$, J. K. Mbadcam ${ }^{a}$, V. S. Safont ${ }^{c}$, M. \\ Oliva ${ }^{c}$ and J. Andrés ${ }^{c^{*}}$ \\ ${ }^{a}$ Department of Inorganic Chemistry, Faculty of Sciences, University of Yaoundé I, \\ P.O. Box 812 Yaoundé, Cameroon. \\ ${ }^{b}$ Department of Chemistry, High Teacher Training College, University of Yaoundé I, \\ P.O. Box 47 Yaoundé, Cameroon. \\ ${ }^{\mathrm{c}}$ Departamento de Química Física y Analítica, Universitat Jaume I, \\ 12071 Castelló, Spain.
}

\begin{abstract}
In this work we report on the progress that has been made towards gaining an understanding of the molecular mechanism of 1,3-dipolar cycloadditions using the bonding evolution theory (BET). A detailed analysis of the flow of electron density along the reaction pathway of the formal 1,3-dipolar cycloaddition reaction between cyclic nitrones (pyrroline-1-oxide and 2,3,4,5 tetrahydropyridine-1-oxide) and ethyl acrylate, as a case study, allowed the nature of the molecular mechanisms to be characterized.
\end{abstract}

The present study provides a deep insight into the reaction mechanism, based on the electron density rearrangements given by the structural stability domains, and their connection with the bond breaking/forming processes along the reaction pathway. Electron pushing formalism is a powerful tool to describe chemical reactivity. Here, we show how the Lewis structures can be recovered and how curly arrows describe electron density transfers in chemical reaction mechanisms based on the BET results. The reaction mechanism is described by four consecutive events taking place as the reaction progresses: 1) the population of the initial $\mathrm{N}-\mathrm{C}$ double bond is transferred to the $\mathrm{N}$ and $\mathrm{C}$ atoms; 2) the population of the initial double $\mathrm{C}-\mathrm{C}$ bond is transferred to the $\mathrm{C}$ atoms. Along the ortho pathway the next steps are: 3) the $\mathrm{C}-\mathrm{C}$ bond-forming, and 4) the O-C 
bond-forming process. The order of 3) and 4) is inverted in the meta channel. Based on the sequence of the structural stability domains along the intrinsic reaction coordinate, a new synchronicity index is proposed, allowing us to classify and quantify the (a)synchronicity of the 1,3-DC reactions and, therefore, the nature of the reaction mechanism. 


\section{Introduction: State of the art}

A central goal of chemistry is to explain and understand the fundamental features of the formation and cleavage of chemical bonds along the reaction mechanism of a given chemical rearrangement. Many scientific theories and concepts are characterized by their simplicity, thus making them easy to communicate to students and researchers, and such simple concepts have therefore been adopted in chemistry. This endeavor has produced molecular orbital (MO), valence bond (VB), and conceptual density functional (CDF) theories, which have been successfully employed by chemists to understand and rationalize chemical reactivity.

The frontier orbital theory ${ }^{1}$ and the orbital symmetry rules of Woodward and Hoffman $^{2}$ are paradigmatic examples of the possibilities of quantum chemistry within the MO theory. In this sense, MOs allow a chemical bond to be defined as a pair of electrons shared by two or more nuclei, as put forward by Lewis ${ }^{3}$. Further, in the VB theory developed by Pauling ${ }^{4-7}$, the superposition of resonant Lewis structures represents the chemical bonds by localized electron pairs, providing interpretations on the very nature of bonds, the structure of the molecules, and even of their reactivity ${ }^{8,9}$. Robinson's curly arrows maintain Lewis electron pairs to represent the bond-making and bond-breaking events during a chemical reaction progress ${ }^{10}$. Curly arrow pushing remains fundamental to rationalize chemical reactivity in organic chemistry and for writing a molecular mechanism to represent the evolution from the reactants, and how they might then go on to give the observed products via possible intermediates and proposed transition states ${ }^{11}$. Very recently, Knizia and Klein ${ }^{12}$ reported how the rearrangements of bonds can be expressed by curly arrows using transformations of intrinsic bond orbitals along the reaction coordinate.

In the CDF theory, chemical reactivity is analyzed from relevant descriptors such as electronegativity, electronic chemical potential, hardness and softness, and so on $^{13-15}$, or the energies of the highest occupied molecular orbital (HOMO, عHOMO) and the lowest unoccupied molecular orbital (LUMO, eLUMO), that is, the LUMO-HOMO gap (gap $=\varepsilon L U M O-\varepsilon H O M O)$. Over the last decade, doubts about the validity and usefulness of these concepts have emerged from various sources, the deeper reason being based on the fact they are not quantum-mechanical observables and, in addition, are not an explicit functional of the electron density. They are mathematical constructs that approximate reality, and are often complex valued functions. 
Electron density, $\rho(\mathrm{r})$, is a measurable feature and always a real valued function. With the advancement of X-ray diffraction techniques and spin-polarized neutron diffraction, chemists are now able to measure $\rho$ (r). It has been argued that an accurate bonding model must be rooted in something real ${ }^{16,17}$. Therefore, a model of the chemical bond must be rooted in quantum mechanics, provide insight, and possess predictive power ${ }^{18}$. This is why the electron density, $\rho(r)$, is certainly the best choice because it is a local function defined within the exact many-body theory, which can also be extracted from experimental data as well as from first principles methods. From a quantum perspective, the importance of $\rho(\mathrm{r})$, as a fundamental property of an electronic system containing all the information of physical relevance, is highlighted by the Hohenberg-Kohn theorem ${ }^{19}$, i.e., all ground state properties depend on the charge density.

The seminal works of Bader et $a l^{20,21}$ have generated an active research area based on the study of the topology of molecular scalar fields. This area is called quantum chemical topology $(\mathrm{QCT})^{22}$, a branch of theoretical and computational chemistry based on the analysis of the gradient of scalar functions that yields a wealth of calculated chemical information from the wave function of a molecule and/or a crystal. Under this formalism, a molecule or crystal is decomposable into atomic domains (commonly referred to as atomic basins) by means of the topology of the electron density, $\rho(r)$. It uses the (mathematical) language of dynamical systems to obtain chemical insight ${ }^{23}$. QCT may be viewed as a bridge between the picture of the chemical bond derived from the Lewis theory and the first principles quantummechanical methods.

Within the QCT framework, we have decided to use bonding evolution theory $(\mathrm{BET})$, proposed by Krokidis and Silvi ${ }^{24}$, which combines the electronic localization function $(E L F)^{25,26}$ and Thom's catastrophe theory $(\mathrm{CT})^{27}$, to unravel reaction mechanisms ${ }^{28-32}$. A topological analysis of ELF in the line of Bader's atoms-inmolecules approach ${ }^{33}$ can be interpreted as a signature of the electronic-pair distribution, and its topology provides a partition between core and valence regions ${ }^{26,34}$.

BET is composed of a chemical interpretation, provided by ELF, and a mathematical formalism, based on Thom's catastrophe theory, disclosing the basic entities of the theory and their mathematical relationships. This introduces the glue linking the formalism and chemical concepts, such as Lewis structures, electron pair, 
and curly arrows used in the chemical language. Some reviews on the ingredients and applicability of BET to understand and rationalize chemical reactivity have been discussed and scrutinized in more detail elsewhere ${ }^{35-39}$. The identification of the turning points connecting the ELF structural stability domains (SSDs) along the reaction pathway allows for a rigorous characterization of the sequence of electron pair rearrangements taking place during a chemical transformation, such as multiple bond forming/breaking processes, creation/annihilation of lone pairs, transformations of double bonds into single ones or vice versa, and other electronic rearrangements.

The paper is organized as follows: in the next section the reaction mechanism of the 1,3-dipolar cycloaddition (1,3-DC) is discussed on the basis of previous studies. In the third section, the computational details are outlined, and in the subsequent section the results are presented and discussed, and we provide the connection among the chemical bond rearrangements, electron density redistribution throughout the reaction progress, and the concepts introduced within the context of BET. Finally, we summarize our main conclusions.

\section{On the reaction mechanism of 1,3-dipolar cycloadditions}

The 1,3-DC reactions between 1,3-dipoles and dipolarophiles are among the most important and extensively studied reactions in organic chemistry ${ }^{40-45}$. As recently remarked by Raines $e t a l^{46}$, more than half a century has elapsed since this encouraging comment by Huisgen: "If one regards reactions as new only if they have no forerunners, not even singular examples buried in the literature, then 1,3-dipolar additions cannot claim novelty. But if one defines reactions as novel which are for the first time recognized for their generality, scope, and mechanism, the judgment must be different" ${ }^{\prime 47}$.

The concept of dipolar cycloaddition offers a formal description of the overall reaction but not a mechanistic interpretation. In the case of the 1,3-DC reaction the main question is whether the new $\sigma$-bonds that are formed during the interaction of the 1,3dipole with the dipolarophile, and which results in a five-membered ring, occur in a concerted or stepwise mechanism. In addition, cycloaddition can follow different reaction pathways with the presence of intermediates of a biradical or zwitterion character on the potential energy surfaces, which deserve special attention in order to understand the reactivity patterns ${ }^{48-54}$. Therefore, a wide range of reaction paths are 
possible for this type of reactions, from concerted synchronous and concerted asynchronous up to two stages via different types of intermediates. Finding the nature of the reaction mechanism for 1,3-DC reactions has been studied using different procedures.

In the seminal work of Huisgen, the nature of these cycloadditions is defined as concerted pericyclic reactions, according to the Woodward-Hoffmann rules, via a symmetry-allowed $\left(\pi^{4} s+\pi^{2} s\right)$ process. These reactions are characterized by joining two $\pi$ systems at their ends to form a ring compound through the formation of two new sigma bonds via the breaking of two $\pi$ bonds, one from each $\pi$ system, in a concerted process $^{55,56}$. More recently, a plethora of theoretical tools have been employed, based on the values of the distortion and interaction energies proposed by Houk et $a l^{57-60}$ or the analysis of the vibrational modes for the reactants ${ }^{61-64}$. In this context, we can cite the works of Toro-Labbé et al in which the degrees of synchronicity (or non-synchronicity) in different types of cycloadditions are analyzed by means of the reaction force constant $^{65,66}$, reaction electronic flux ${ }^{67}$, and electronic stress ${ }^{68}$, which have been shown to be effective for this purpose. Very recently, Cremer et al ${ }^{69}$ analyzed the reaction mechanism of the cycloaddition of ten 1,3-dipoles with two dipolarophiles (ethylene and acetylene) using the unified reaction valley approach. As a general conclusion these authors point out a caveat with regard to oversimplified descriptions of the reaction mechanism based on orbital theory or energy decomposition schemes.

The case study: the reaction mechanism of 1,3-dipolar cycloadditions between the cyclic nitrones and ethyl acrylate

1,3-DC is widely used in organic chemistry for the preparation of five-membered heterocycles, which are synthetically useful compounds ${ }^{40}$, due to their high stereospecificity and stereoselectivity ${ }^{70-72}$. In this context, 1,3-DC reactions between nitrones and alkenes leading to isoxazolidines are well-known construction processes ${ }^{73}$. Isoxazolidines are found in several biologically active molecules with different uses, such as plant growth regulators, antiviral, antibiotic, and antitumor drugs, and fungicides. Due the presence of a labile $\mathrm{N}-\mathrm{O}$ bond, isoxazolidines act as intermediates in the synthesis of alkaloids, and they can be easily converted into 1,3 aminoalcohols, aminoacids, substituted amines, nitroalcohols, $\beta$ enamine-carbonyls, and so forth ${ }^{74-77}$. These 1,3-DC reactions of nitrones with dipolarophiles can lead to the formation of both 
endo and exo isoxazolidines cycloadducts, and their corresponding mechanism has been the subject of many theoretical studies ${ }^{78-83}$.

It is important to underline that the majority of these works are focused on the analysis of the stationary points on the potential energy surface, as well as on the reactivity indices derived from CDF theory. Very recently, Miranda-Quintana and Ayers $^{84}$ revisited the role of some reactivity descriptors of CDF theory, such as the electronic chemical potential, as an indicator of the tendency of chemical species to attract or donate electrons, in a family of 1,3-DC reactions. These authors observe that the direction of the electron transfer is incorrectly predicted by the classical Mulliken electronegativity formula. Therefore, mechanistic aspects of this type of reactions present shortcomings and necessarily require a deep re-examination.

Some time ago we studied the molecular mechanism of the 1,3-DC between fulminic acid and acetylene by means of BET and the results provided a chemical description of the reaction mechanism in terms of heterolytic concerted nonsynchronous bond formation: the first step corresponding to the simultaneous formation of the C-C bond and a lone pair on the nitrogen atom, whereas the remaining ones lead to ring closure $^{30}$. We therefore proposed that the term 1,3-DC reaction is widely overused and deserve clarification.

In the present work, a systematic study of the mechanistic aspects of the formal 1,3-DC reaction between the cyclic nitrones pyrroline-1-oxide (1) and 2,3,4,5 tetrahydropyridine-1-oxide (2) with ethyl acrylate (Scheme 1) to obtain bicyclic isoxazolidines, are analyzed and described from the perspective of BET. This work aims to give rise to new breakthrough points on the nature of the molecular mechanism of these reactions. In particular, concertedness and synchronicity/nonsynchronicity, which are relevant concepts able to establish temporal relationships between the chemical events that lead to chemical reactivity. Likewise, the present approach retrieves the classical curly arrows used to describe the rearrangements of chemical bonds for a given reaction mechanism, from the electron flows accompanying the bond breaking/forming processes as described by the BET, and how the Lewis structure can be recovered. Some of us ${ }^{85}$ have recently revisited this strategy. 
CAnoen

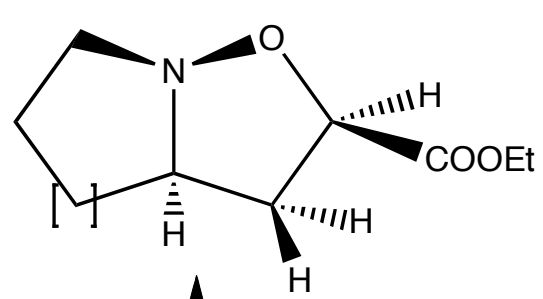

CAnoex

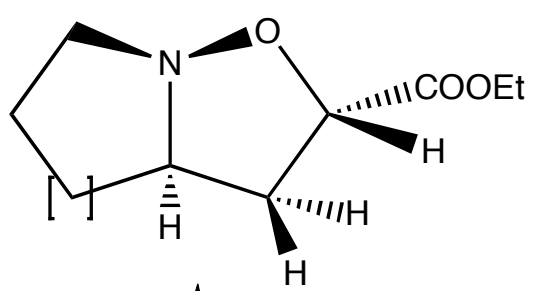

$\uparrow \mathrm{H}$

TSnoen

TSnoex

Ortho Channel<smiles>C=CC(OCC)OCC</smiles>

$n=1,2$

Meta Channel

TSnmen

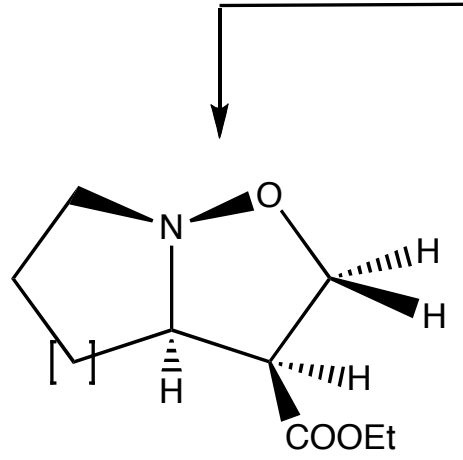

CAnmen
TSnmex

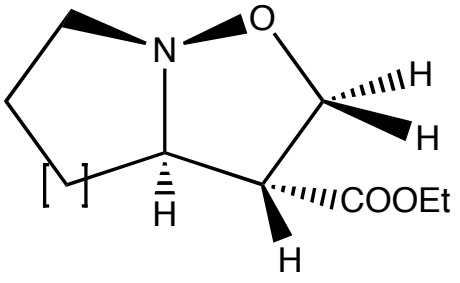

CAnmex

Scheme 1. 1,3-DC reactions of cyclic nitrones $\mathbf{1}(n=1)$ and $\mathbf{2}(n=2)$ with ethyl acrylate along ortho and meta- channels.

\section{Computational details}

All calculations of structures and energetics were carried out with the aid of Gaussian $03^{86}$ or Gaussian $09^{87}$ sets of programs. Geometrical parameters of reactants, transition states (TS) and products were fully optimized at several theoretical levels for nitrone 1, ranging from AM1 to wB97xd/cc-pVTZ. For nitrone 2, the B3LYP/6-31G(d) and M06-2x/6-311++G** levels have been used (see below). The TSs were further confirmed by vibrational analysis and characterized by the only one imaginary vibrational mode. The IRC paths ${ }^{88}$ were traced in order to check the energy profiles 
connecting each TS to the two associated minima of the proposed mechanism using the second-order González-Schlegel integration method ${ }^{89,90}$. The electronic structures of the stationary points were also analyzed by the natural bond orbital (NBO) method ${ }^{91}$.

For the topological analysis within the BET theory, the wave functions have been obtained for each point of the IRCs at the B3LYP/6-31G(d) and M06-2X/6$311++\mathrm{G}^{* *}$ levels for nitrone 1, and at the B3LYP/6-31G(d) for nitrone 2, and the ELF analysis has been performed by means of the TopMod package ${ }^{92}$ considering a cubical grid of step size smaller than 0.05 bohr. The molecular geometries and ELF basin positions are visualized using the program GaussView ${ }^{93}$. The pictorial representations of the ELF basin isosurfaces (see supporting information) has been done by using the program UCSF Chimera ${ }^{94}$.

The topologies of the ELF gradient fields along the reaction pathway connecting reactants with products, via transition structures and possible intermediates, cover a series of SSDs, within which all the critical points are hyperbolic, separated by catastrophic points at which at least one critical point is non-hyperbolic. The catastrophes occurring at these turning points are identified according to Thom's classification $^{27}$. Therefore, a chemical rearrangement is viewed as a sequence of elementary chemical processes separated by turning points or catastrophes. These chemical processes are classified according to the variation of the number of basins $\mu$ and/or of the synaptic order $\sigma$ of at least one basin. A clarification about the meaning of atomic basins, SSDs, terms and terminologies can be found in previous studies ${ }^{36,37,95,96}$.

\section{Results and discussion}

\section{Energetic and geometric aspects}

Four reactive channels are possible for these formal 1,3-DC from two regioisomeric pathways (ortho and meta), as shown in Scheme 1. We used the name system for the corresponding TSs and cycloadducts, with $n=1$ or 2 for the processes starting from nitrones $\mathbf{1}$ or $\mathbf{2}$, respectively.

The energetic values obtained are summarized in Tables 1 and 2. Table 1 shows the activation enthalpies and Gibbs free energies for the 1,3-DC between nitrone 1 and ethyl acrylate at the various theoretical levels used. As can be seen, the values obtained are strongly dependent on the theoretical level, either from a quantitative or from a 
qualitative point of view. This dependence has already been noted by Acharjee et al ${ }^{81}$ and earlier by Carda et $a l^{97}$, and was explained based on the similar HOMO coefficient values that related nitrones exhibit at the oxygen and ethylene carbon centers.

Three of the theoretical levels used predict the ortho-endo channel to be the preferred one, while four of them conclude that TS1men is the most favorable TS. The energetic differences between the calculated barrier heights are relatively small within each of the methods used, with the exception of the HF/Def2TZV values. They are always lower than $5.5 \mathrm{kcal} / \mathrm{mol}$, thus indicating that from a theoretical point of view the four channels can compete to some extent. Both endo paths emerge as the most preferred, in agreement with the endo stereoselectivity observed with acyclic nitrones ${ }^{83}$. As can be seen in Table 1, with the exception of the results obtained at HF/Def2TZV, the endo approach via the ortho- pathway is favored over the exo approach. In the metapathway the endo approach is also in general more favorable, although several differences have been found.

Table 1: Activation enthalpies $\left(\Delta H^{\#}\right)$ and Gibbs free energies $\left(\Delta G^{\#}\right)$ with respect to the separated reactants, both in $\mathrm{kcal} / \mathrm{mol}$, for the TSs found in the 1,3-DC reaction of nitrone 1 with ethyl acrylate at the theoretical levels indicated. The lowest values obtained at each theoretical level are highlighted in red.

\begin{tabular}{|c|c|c|c|c|c|}
\hline & & TS1oen & TS1oex & TS1men & TS1 mex \\
\hline \multirow{2}{*}{ AM1 } & $\Delta \mathrm{H}^{\#}$ & 20.08 & 21.84 & 17.73 & 18.55 \\
\cline { 2 - 6 } & $\Delta \mathrm{G}^{\#}$ & 33.95 & 35.24 & 30.94 & 31.39 \\
\hline \multirow{2}{*}{ B3LYP/6-31G(d) } & $\Delta \mathrm{H}^{\#}$ & 9.54 & 10.90 & 10.36 & 10.65 \\
\cline { 2 - 6 } & $\Delta \mathrm{G}^{\#}$ & 23.43 & 23.86 & 24.07 & 23.75 \\
\hline B3LYP/6-311++G** & $\Delta \mathrm{H}^{\#}$ & 14.32 & 14.71 & 15.00 & 14.61 \\
\cline { 2 - 6 } & $\Delta \mathrm{G}^{\#}$ & 27.96 & 28.01 & 28.45 & 27.83 \\
\hline \multirow{2}{*}{ HF/Def2TZV } & $\Delta \mathrm{H}^{\#}$ & 31.16 & 31.03 & 21.52 & 21.44 \\
\cline { 2 - 6 } & $\Delta \mathrm{G}^{\#}$ & 45.31 & 44.84 & 35.29 & 34.98 \\
\hline MP2/6-31G(d) & $\Delta \mathrm{H}^{\#}$ & -2.18 & -1.39 & 2.53 & 3.34 \\
\cline { 2 - 6 } & $\Delta \mathrm{G}^{\#}$ & 11.61 & 12.07 & 15.74 & 16.64 \\
\hline B97D/cc-pVTZ & $\Delta \mathrm{H}^{\#}$ & 5.43 & 6.66 & 7.77 & 8.46 \\
\cline { 2 - 6 } & $\Delta \mathrm{G}^{\#}$ & 19.32 & 19.62 & 21.62 & 21.82 \\
\hline M06-2X/6-311++G** & $\Delta \mathrm{H}^{\#}$ & 6.69 & 7.53 & 4.21 & 5.98 \\
\cline { 2 - 6 } & $\Delta \mathrm{G}^{\#}$ & 20.91 & 21.36 & 18.43 & 19.10 \\
\hline \multirow{2}{*}{ wB97xd/cc-pVTZ } & $\Delta \mathrm{H}^{\#}$ & 8.49 & 9.51 & 7.47 & 8.54 \\
\cline { 2 - 6 } & $\Delta \mathrm{G}^{\#}$ & 22.73 & 23.29 & 21.73 & 22.03 \\
\hline
\end{tabular}




\begin{tabular}{|c|c|c|c|c|c|}
\hline M06-2X/cc-pVTZ & $\Delta \mathrm{H}^{\#}$ & 7.70 & 8.51 & 5.32 & 6.60 \\
\cline { 2 - 6 } & $\Delta \mathrm{G}^{\#}$ & 22.03 & 22.44 & 19.79 & 20.03 \\
\hline
\end{tabular}

For this kind of reactions, the chemical intuition indicates that the most nucleophilic center of the nitrone should attack the most electrophilic center of the dipolarophile. We have calculated the local electrophilicities and nucleophilicities (data not shown) for nitrone $\mathbf{1}$ and ethyl acrylate at the theoretical levels used, and we have confirmed that, whatever the method, the most nucleophilic center of nitrone $\mathbf{1}$ is predicted to be the oxygen atom, while the most electrophilic center of the dipolarophile is the terminal ethylene carbon atom. The nucleophilic attack of the nitrone on ethyl acrylate would therefore explain the formation of a meta regioisomer. However, we cannot rule out the possibility of an ortho-endo channel according to the energetic data obtained, and therefore in what follows both the ortho-endo and meta-endo channels have been studied in depth, by using either one of the methods that predict the orthoendo channel as the more favorable pathway, and also by using one of the methods that predict the meta-endo channel as the preferred one. Among the first ones we have chosen the B3LYP/6-31G(d) theoretical level because the MP2/6-31G(d) and the B97D/cc-pVTZ approaches require unattainable calculation times when conducting the topological analysis. Among the second ones we have chosen the M06-2X/6-311++G** because the other non-semiempirical methods predicting the meta-endo channel to be the preferred path (wB97xd/cc-pVTZ and M06-2X/cc-pVTZ) also require too long calculation times. Table 2 shows the relative enthalpies and Gibbs free energies of all the stationary points calculated by using these two theoretical approaches.

Table 2: Relative (to reactants) enthalpies $(\Delta \mathrm{H})$ and Gibbs free energies $(\Delta \mathrm{G})$, both in $\mathrm{kcal} / \mathrm{mol}$, for the stationary points found in the 1,3-DC reaction of nitrones $\mathbf{1}$ and $\mathbf{2}$ with ethyl acrylate.

\begin{tabular}{|c|c|c|c|c|}
\hline & \multicolumn{2}{|c|}{ B3LYP/6-31G(d) } & \multicolumn{2}{|c|}{ M06-2X/6-311++G** } \\
\hline & $\Delta \mathrm{H}$ & $\Delta \mathrm{G}$ & $\Delta \mathrm{H}$ & $\Delta \mathrm{G}$ \\
\hline TS1oen & 9.54 & 23.43 & 6.69 & 20.91 \\
\hline TS1oex & 10.90 & 23.86 & 7.53 & 21.36 \\
\hline TS1men & 10.36 & 24.07 & 4.21 & 18.43 \\
\hline TS1mex & 10.65 & 23.75 & 5.98 & 19.10 \\
\hline TS2oen & 10.67 & 24.30 & 7.74 & 21.45 \\
\hline TS2oex & 11.67 & 25.01 & \begin{tabular}{|l|}
8.61 \\
\end{tabular} & 22.47 \\
\hline
\end{tabular}




\begin{tabular}{|l|l|l|l|l|}
\hline TS2men & 8.87 & 23.02 & 2.51 & 16.75 \\
\hline TS2mex & 11.13 & 24.56 & 6.25 & 19.51 \\
\hline CA10en & -17.04 & -2.63 & -26.32 & -11.58 \\
\hline CA10ex & -16.57 & -2.86 & -26.07 & -12.22 \\
\hline CA1men & -16.31 & -2.23 & -26.81 & -11.92 \\
\hline CA1mex & -17.51 & -3.69 & -27.33 & -13.67 \\
\hline CA2oen & -16.21 & -2.44 & -25.42 & -10.94 \\
\hline CA2oex & -15.29 & -1.70 & -24.72 & -10.88 \\
\hline CA2men & -15.24 & -0.99 & -26.74 & -11.64 \\
\hline CA2mex & -15.60 & -1.70 & -26.42 & -12.20 \\
\hline
\end{tabular}

At the B3LYP/6-31G(d) level, for nitrone $\mathbf{1}$ it is predicted that the passage through TS1oen is kinetically favored, while the obtaining of CA1mex via TS1mex is thermodynamically favored. In contrast, at M06-2X/6-311++G**, the passage through TS1men is predicted to be kinetically favored, the formation of CA1mex also being predicted as the preferred pathway from a thermodynamic point of view. The values listed in Table 2 indicate that this reaction is moderately regioselective, because the energy differences between the most favorable TS and the least favorable one are very small, and also display a moderate endo stereoselectivity as the endo TSs are a few kcal $\mathrm{mol}^{-1}$ below the exo TSs. For nitrone 2, both calculation levels predict TS2men to be the most favorable TS, the differences with the other TSs being slightly larger than in the case of nitrone 1, although they are still small. The exothermic nature of the reaction makes the formation of the four cycloadducts irreversible, and therefore the main products of the reactions are the ones which are formed by kinetic control. However, given the small energetic differences among all TSs, a mixture of the four cycloadducts can be obtained.

The transition structures are depicted in Figures 1 and 2 for the starting nitrones $\mathbf{1}$ and 2, respectively. Their geometries are fairly invariant with respect to the theoretical level used (see Table 1S in Supporting Information).

Some B3LYP/6-31G(d) distances are included in Figures 1 and 2, together with the corresponding Wiberg bond orders obtained at the TS, and show that C-C bond formation is more advanced in the ortho channels, while C-O bond formation is more advanced in the meta channels. Thus, the C-O bond orders at the TS for the ortho channels range from 0.263 to 0.287 , while the $\mathrm{C}-\mathrm{C}$ bond orders can be found between 0.465 and 0.487 . Therefore, at the TS the C-C bond formation is roughly 1.7 or 1.8 
times more advanced than the $\mathrm{C}-\mathrm{O}$ bond formation. With respect to the meta channels, the $\mathrm{C}-\mathrm{O}$ bond orders range between 0.467 and 0.523 , while the $\mathrm{C}-\mathrm{O}$ bond indices are between 0.313 and 0.326 , and hence $\mathrm{C}-\mathrm{O}$ bond formation is approximately 1.5 or 1.6 times more advanced at the TS than C-C bond formation.

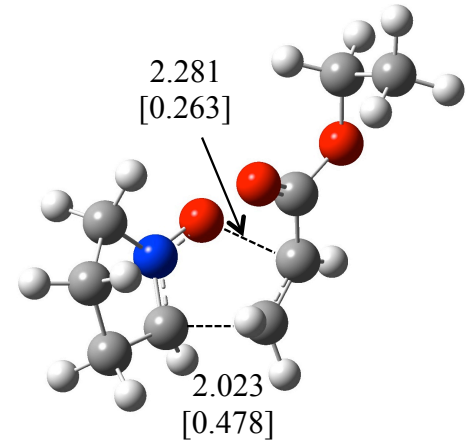

TS1oen

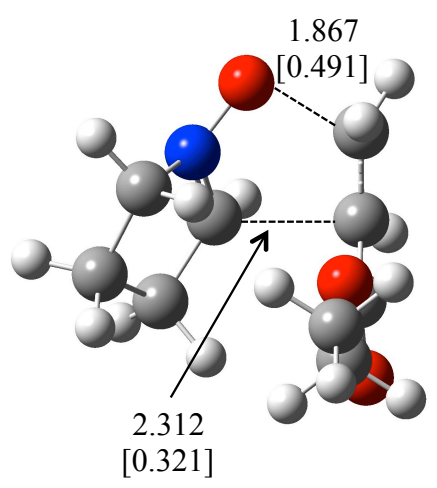

TS1men

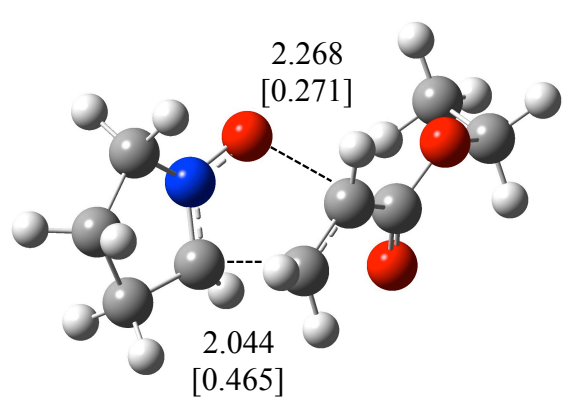

TS10ex

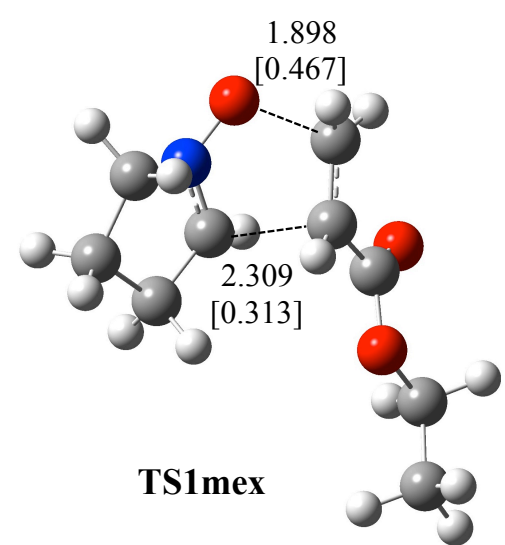

Figure 1: Optimized geometries at the B3LYP/6-31G(d) level for the TS1 structures with bond order (Wiberg bond index) in brackets. 


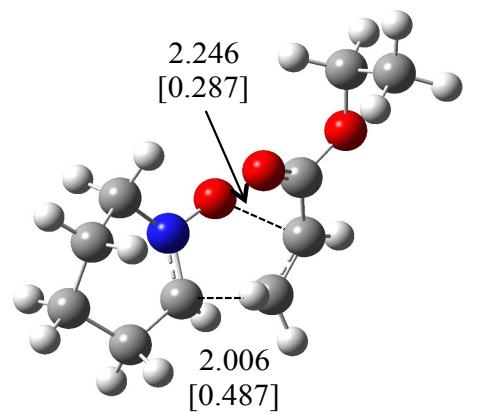

TS2oen

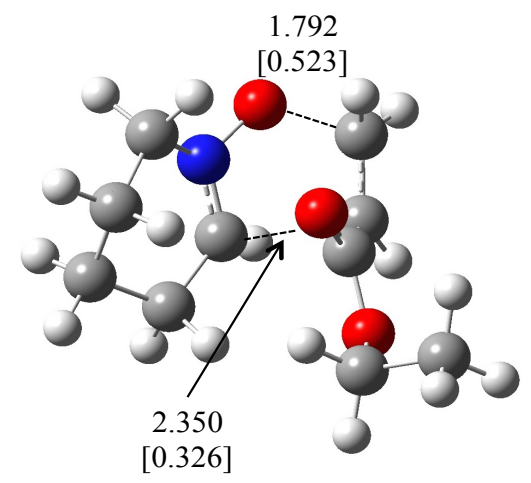

TS2men

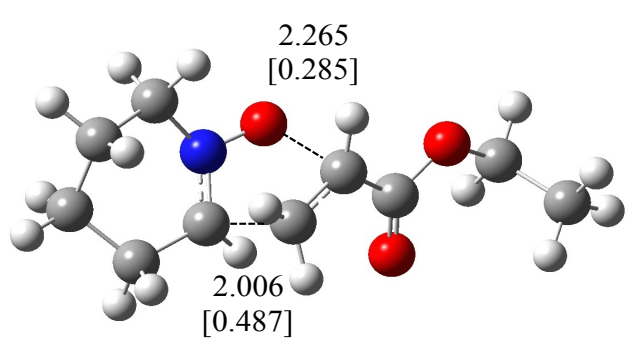

TS2oex

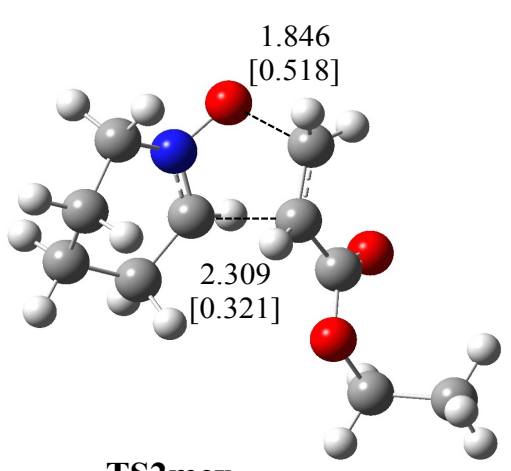

TS2mex

Figure 2: Optimized geometries at the B3LYP/6-31G(d) level for the TS2 structures with bond order (Wiberg bond index) in brackets.

A charge transfer analysis at the transition structures can be found in the supporting information. The results indicate that the electron flux will occur from nitrones to ethyl acrylate, in agreement with the DFT reactivity indices derived from $\mathrm{CDT}$, as can also be seen in tables $2 \mathrm{~S}$ and $3 \mathrm{~S}$ in the supporting information.

\section{BET study of the ortho/endo regioisomeric pathway for nitrone 1}

We have conducted a detailed BET study of the ortho/endo regioisomeric pathway associated with the 1,3-DC reaction between ethyl acrylate and pyrroline-1oxide at the B3LYP/6-31G(d) level and at the M06-2X/6-311++G** level to test the robustness of the topological study and its dependence on the theoretical level at which the wave functions have been obtained. Both methods describe the process along seven SSDs, although some differences can be sensed. In Figure 3 the positions of the ELF basins for representative points belonging to each of the seven SSDs are shown, together with the position of the ELF basins for the isoxazolidine product, as obtained at the M06-2X/6-311++G** level. 


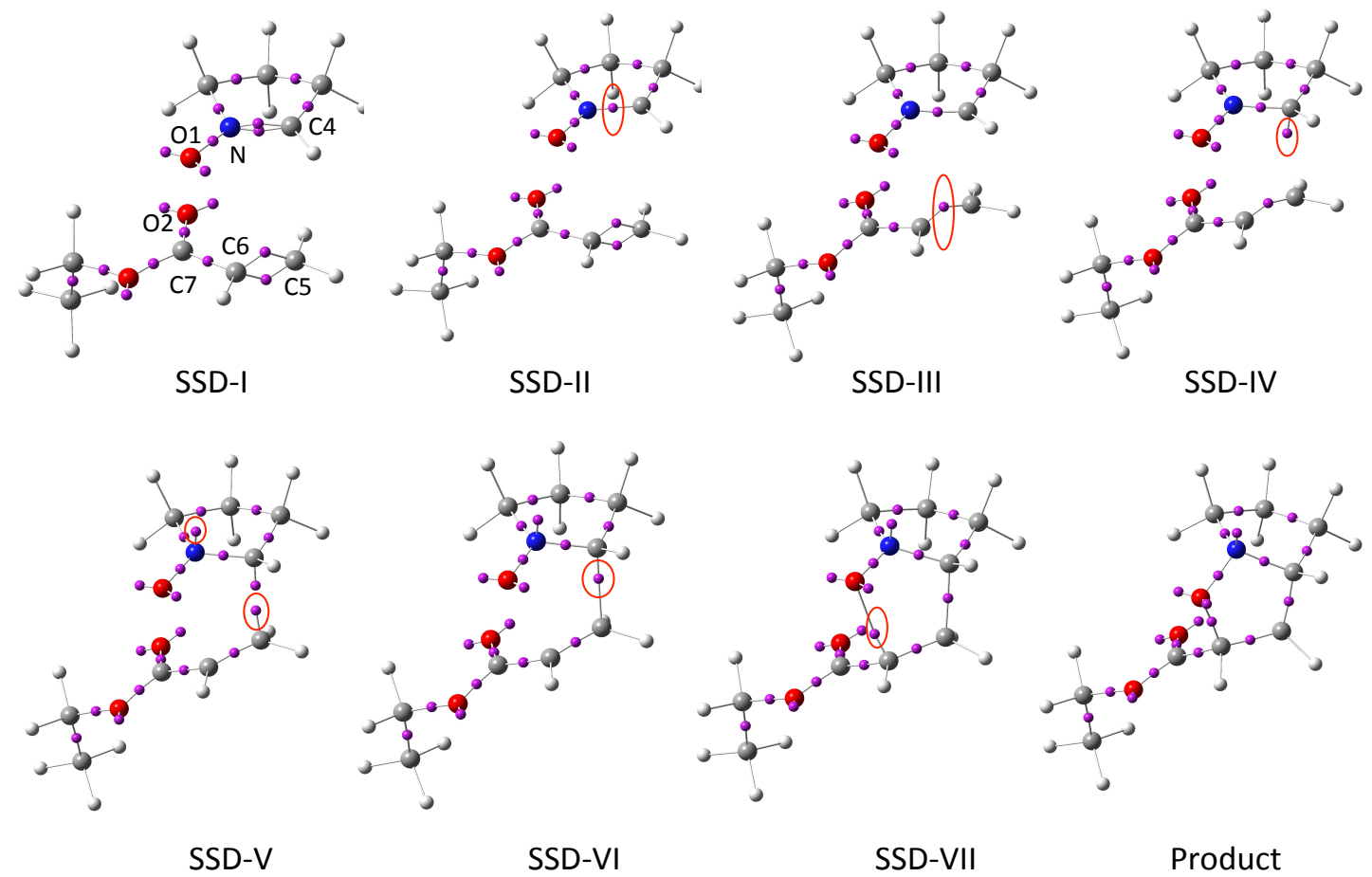

Figure 3. ELF attractor positions for selected points that are representative of each of the SSDs found along the IRC associated with TS1oen, as well as for the reaction product. Gray, blue and red spheres represent the $\mathrm{C}, \mathrm{N}$, and $\mathrm{O}$ core basins, respectively. White spheres represent the hydrogenated basins, while violet spheres represent disynaptic or monosynaptic basins. The numbering used for some atoms is also shown, and a red ellipse has been used to highlight the topological changes encountered.

As can be seen in Figure 3, in SSD-I the system shows the topologies of the separate reactants. Therefore, 22 basins can be found in the pyrroline moiety: the six core basins for the $\mathrm{O}, \mathrm{N}$ and $\mathrm{C}$ atoms, seven hydrogenated basins, seven disynaptic basins accounting for the bonds between heavy atoms, and two monosynaptic basins around the $\mathrm{O} 1$ atom. For the acrylate moiety, 25 basins can be found: seven core basins, eight hydrogenated basins, seven disynaptic basins and three monosynaptic basins around the $\mathrm{O}$ atoms.

When performing the analysis at the B3LYP/6-31G(d) level, only one disynaptic basin appears between $\mathrm{N}$ and $\mathrm{C} 4$ at the beginning of the reaction (see Figure $2 \mathrm{~S}$ in Supporting information). This discrepancy in the number of disynaptic basins between the $\mathrm{N}$ and $\mathrm{C} 4$ atoms has only been found in the ortho/endo case (see below). It must be stated that the difference between the results obtained with the two methods only affects the number of basins, but not the electronic distribution, because the total population of the two separated $\mathrm{V}(\mathrm{N}, \mathrm{C} 4)$ basins found at both levels approaches four electrons, as 
expected. In Figure 1S, in Supporting information, a pictorial representation of the ELF localization domains as obtained by using both calculation levels is depicted. As can be seen, the pictorial description is the same despite this difference in the number of basins between $\mathrm{N}$ and $\mathrm{C} 4$. These two disynaptic basins between $\mathrm{N}$ and $\mathrm{C} 4$ merge into one by means of a cusp-type turning point well before the rest of the topological changes take place, without affecting the electronic distribution of the system (see below).

As the reaction proceeds, the merging of the two disynaptic basins between $\mathrm{C} 5$ and $\mathrm{C} 6$ atoms by means of a cusp-type turning point occurs. Soon after that, a fold-type catastrophe takes place, consisting in the appearance of a monosynaptic basin on $\mathrm{C} 4$ when SSD-IV is reached, pointing to the C5 atom as can be seen. Then other monosynaptic basins appear on the $\mathrm{N}$ and $\mathrm{C} 5$ atoms, in a fold-type turning point, when SSD-V is attained. The TS is reached in the middle of the SSD-V region, and SSD-VI begins with the formation of the $\mathrm{C} 4-\mathrm{C} 5$ bond when both monosynaptic basins on $\mathrm{C} 4$ and $\mathrm{C} 5$ atoms merge with each other and a new disynaptic $\mathrm{V}(\mathrm{C} 4, \mathrm{C} 5)$ basin appears instead, in a cusp catastrophe. The last topological change takes place when SSD-VII is reached, and consists in the sudden appearance of the $\mathrm{V}(\mathrm{O} 1, \mathrm{C} 6)$ disynaptic basin accounting for the O1-C6 bond formation, by means of another cusp-type turning point. The description of the main changes is invariant regardless of the theoretical level used: the appearance of monosynaptic basins on $\mathrm{N}$ and both carbon atoms (in this case, first the $\mathrm{C} 4$, then $\mathrm{N}$ and $\mathrm{C} 5)$ precedes the formation of the disynaptic $\mathrm{V}(\mathrm{C} 4, \mathrm{C} 5)$ basin and, finally, $\mathrm{V}(\mathrm{O} 1, \mathrm{C} 6)$.

The population evolution along the IRC for the most representative basins has been depicted in Figure 4 (see Figure 3S in Supporting Information for the B3LYP results). The separation between the different SSDs found is indicated with the help of dashed vertical lines. As can be seen, along SSD-I and SSD-II nothing seems to happen from an electronic point of view, apart from the initial merging of the disynaptic basins between $\mathrm{N}$ and $\mathrm{C} 4$ atoms that does not affect the population distribution, making apparent the idea that the turning point between SSD-I and SSD-II lacks significance from an electronic point of view. The two reactants approach each other without electronic transfer: only near the end of the SSD-II a very slight decrease in the V'(C5,C6) disynaptic basin population, and a slight increase in the V(N,C4) basin population, can be detected.

The figure 4 makes apparent that, with the exception of the first non-significant change, the turning points concentrate in a relatively narrow region around the TS, and 
therefore, although the whole process cannot be described as concerted from a topological point of view because different chemical events take place successively, the changes between SSDs occur very close to each other, in a highly synchronous way.

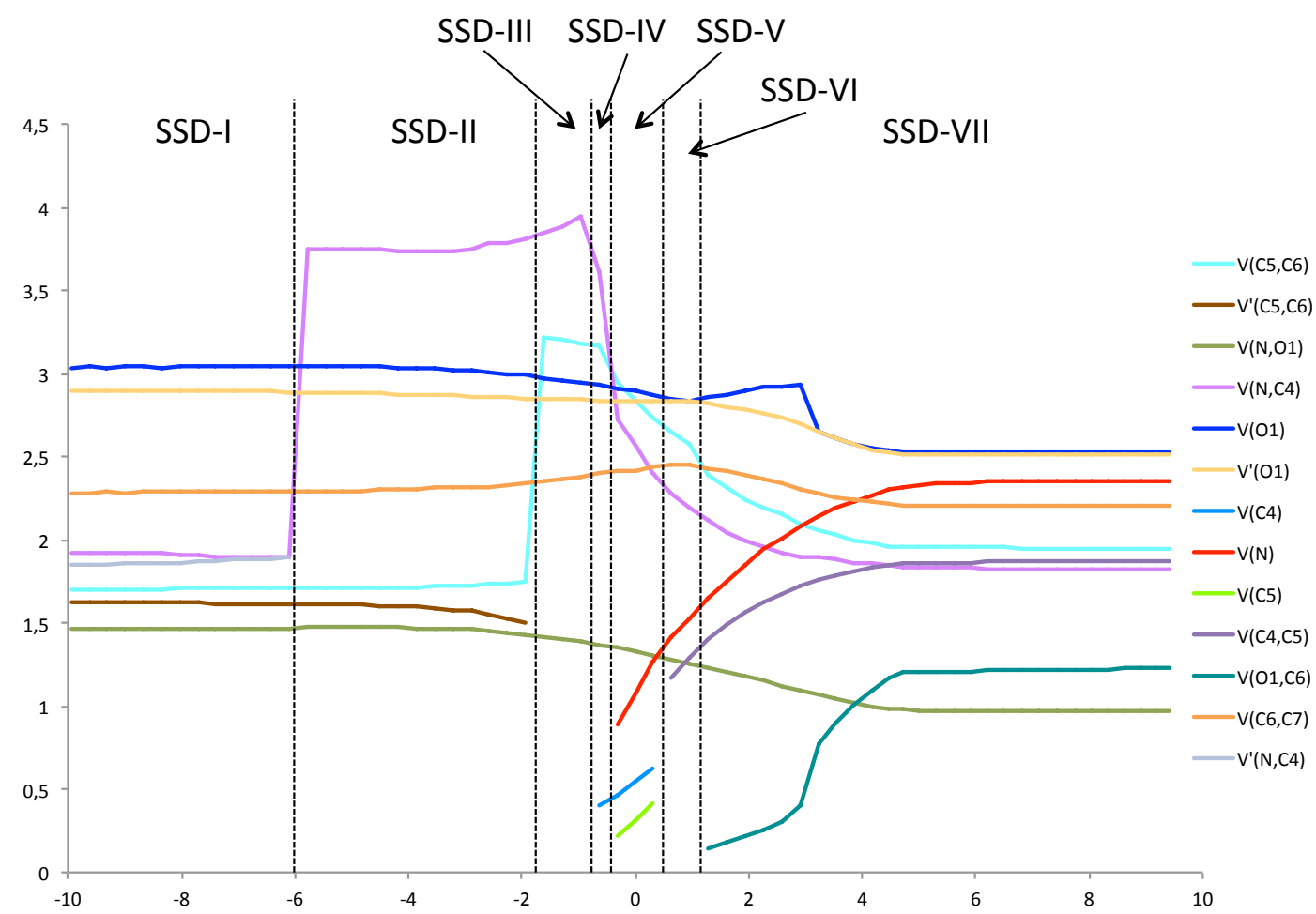

Figure 4. Population (in electrons) evolution of selected basins along the IRC associated with TS1oen as a function of the IRC coordinate (in $\mathrm{amu}^{1 / 2} \cdot$ bohr) as obtained at the M06-2X/6-311++G** level. The separate reactants are located on the left, while the product of the cycloaddition is on the right. Dashed lines indicate the frontiers between the SSDs found.

Concertedness and synchronicity are fundamental concepts in chemical reactivity that are used to define the nature of a given reaction mechanism. These concepts allow us to establish a temporal relation between the chemical bond formation/rupture processes along the progress of the reaction. If these processes occur at the same time, the reaction mechanism is defined as concerted synchronous, but if they occur at different times, one after another, it is said that the reaction mechanism is asynchronous. A deep relationship between these temporal concepts and spatial quantities can be found by analyzing SSDs. To verify the validity of this statement and use the position of the changes between the different SSDs as an indicator of the synchronicity of a particular process, we define the following equations to be used when the number of SSDs is at least three: 


$$
S y=1-\frac{2}{n(n-1)\left(S_{f}-S_{0}\right)} \sum_{i=1}^{n} \sum_{j=i+1}^{n}\left(S_{j}-S_{i}\right)
$$

Equation (1) allows us to calculate the synchronicity (Sy), the maximum value of which will be 1 . In the equation, $n$ is the number of SSDs minus one, $S_{f}$ and $S_{0}$ are the final and initial IRC values, respectively, and the different values of $S_{j}$ and $S_{i}$ are the IRC values at which the changes between SSDs appear. The closer they are, the more the Sy value approaches 1 . The minimum value of Sy will be a function of $n$, being zero for $n=2,0.333$ for $n=3$ or $4,0.4$ for $n=5$ or 6 , and so on. This minimum Sy value can be obtained by using equation (2):

$$
S y^{\min }=1-\frac{2\left(\sum_{i=1}^{n}(n-i)-\sum_{i=1}^{n / 2}(n-2 i)\right)}{n(n-1)}
$$

To obtain an absolute synchronicity, $\mathrm{Sy}^{\mathrm{abs}}$, on a zero-to-one scale, equation (3) is used:

$$
S y^{a b s}=\frac{S y-S y^{\min }}{1-S y^{\min }}
$$

In our case, when neglecting the aforementioned non-significant change relative to the initial number of basins between $\mathrm{C} 4$ and $\mathrm{N}, n=5$ and therefore $\mathrm{Sy}^{\mathrm{min}}=0.4$. The IRC ranges from -9.94 to $9.41 \mathrm{amu}^{1 / 2}$ bohr, and the values for the rest of the SSD changes are, from left to right, in $\mathrm{amu}^{1 / 2} \cdot \mathrm{bohr},-1.77 ;-0.80 ;-0.48 ; 0.48$ and 1.13 . Hence Sy is calculated to be 0.93 and $\mathrm{Sy}^{\mathrm{abs}}=0.88$. This value implies that the topological changes take place in a very synchronous way, at $88 \%$ of the maximum absolute synchronicity. In addition, it should be noted that the TS can be found roughly midway along the IRC (at approximately 51\%), and therefore it has an intermediate nature between reactants and products in terms of its position along the IRC pathway. The B3LYP results are equivalent, and a highly synchronous process is also described $\left(\mathrm{Sy}^{\mathrm{abs}}=0.85\right)$. The TS can also be found at approximately $51 \%$ of the IRC. These data are shown in Table 4 to facilitate their interpretation. 
Table 4: Absolute synchronicities $\left(\mathrm{Sy}^{\mathrm{abs}}\right)$; percentage of the IRC where the TS is located (\%IRC), number of domains found $(\mathrm{N})$ and order in which the monosynaptic and disynaptic basins appear (order) along the four pathways studied for the two nitrones at the B3LYP/6-31G(d) level. In brackets, the values obtained at the M06-2X/6-311++G** level.

\begin{tabular}{|c|c|c|c|c|}
\hline Nitrone & ortho/endo & ortho/exo & meta/endo & meta/exo \\
\hline & \multicolumn{4}{|c|}{$\mathrm{Sy}^{\mathrm{abs}}$} \\
\hline 1 & $0.85[0.88]$ & $0.88[0.91]$ & $0.76[0.79]$ & $0.80[0.89]$ \\
\hline \multirow[t]{2}{*}{2} & 0.87 & 0.92 & 0.73 & 0.82 \\
\hline & \multicolumn{4}{|c|}{ \%IRC } \\
\hline 1 & $51.1 \%[51.4 \%]$ & $53.8 \%[63.1 \%]$ & $56.3 \%[46.2 \%]$ & $56.9 \%[46.6 \%]$ \\
\hline \multirow[t]{2}{*}{2} & $52.1 \%$ & $43.8 \%$ & $51.4 \%$ & $55.2 \%$ \\
\hline & \multicolumn{4}{|c|}{$\mathrm{N}$} \\
\hline 1 & $7[7]$ & $6[7]$ & $7[6]$ & $7[7]$ \\
\hline \multirow[t]{2}{*}{2} & 7 & 6 & 6 & 7 \\
\hline & \multicolumn{4}{|c|}{ order } \\
\hline $1 *$ & $\begin{array}{l}\mathrm{C} 4 ; \mathrm{N} ; \mathrm{C} 5 ; \mathrm{C}-\mathrm{C} ; \\
\mathrm{C}-\mathrm{O} \\
{[\mathrm{C} 4 ; \mathrm{N}+\mathrm{C} 5 ; \mathrm{C}-\mathrm{C} ;} \\
\mathrm{C}-\mathrm{O}]\end{array}$ & $\begin{array}{l}\mathrm{C} 4 ; \mathrm{N} ; \mathrm{C} 5 ; \mathrm{C}-\mathrm{C} ; \\
\mathrm{C}-\mathrm{O} \\
{[\mathrm{N} ; \mathrm{C} 4 ; \mathrm{C} 5 ; \mathrm{C}-\mathrm{C} ;} \\
\mathrm{C}-\mathrm{O}]\end{array}$ & $\begin{array}{l}\mathrm{N} ; \mathrm{C} 6 ; \mathrm{C} 4 ; \mathrm{C}-\mathrm{O} ; \\
\mathrm{C}-\mathrm{C} \\
{[\mathrm{N} ; \mathrm{C} 6 ; \mathrm{C} 4+\mathrm{C}-\mathrm{O} ;} \\
\mathrm{C}-\mathrm{C}]\end{array}$ & $\begin{array}{l}\mathrm{N} ; \mathrm{C} 6 ; \mathrm{C} 4 ; \mathrm{C}-\mathrm{O} ; \\
\mathrm{C}-\mathrm{C} \\
{[\mathrm{N} ; \mathrm{C} 6 ; \mathrm{C} 4 ; \mathrm{C}-\mathrm{O} ;} \\
\mathrm{C}-\mathrm{C}]\end{array}$ \\
\hline 2 & $\begin{array}{l}\mathrm{C} 4 ; \mathrm{N} ; \mathrm{C} 5 ; \mathrm{C}-\mathrm{C} ; \\
\mathrm{C}-\mathrm{O}\end{array}$ & $\begin{array}{l}\mathrm{C} 4+\mathrm{N} ; \mathrm{C} 5 ; \mathrm{C}-\mathrm{C} ; \\
\mathrm{C}-\mathrm{O}\end{array}$ & $\begin{array}{l}\mathrm{N}+\mathrm{C} 6 ; \quad \mathrm{C} 4 ; \mathrm{C}-\mathrm{O} ; \\
\mathrm{C}-\mathrm{C}\end{array}$ & $\begin{array}{l}\mathrm{N} ; \mathrm{C} 6 ; \mathrm{C} 4 ; \mathrm{C}-\mathrm{O} ; \\
\mathrm{C}-\mathrm{C}\end{array}$ \\
\hline
\end{tabular}

* The appearance of monosynaptic basins is indicated with the atomic symbols and atom numbering, while the appearance of the disynaptic basins is only indicated with $\mathrm{C}-\mathrm{C}$ or $\mathrm{C}-\mathrm{O}$, depending on the bond formed.

The data presented in Figure 4 can be used to describe the flows of electrons, and the intimate electronic mechanism of the reaction process can be revealed. As mentioned above, when SSD-III is reached the disynaptic basins $\mathrm{V}(\mathrm{C} 5, \mathrm{C} 6)$ and V'(C5,C6) merge to render a single basin between these two atoms with a population that initially equates the sum of the populations of the separate basins, and from this turning point onwards the electronic redistribution takes place.

Then SSD-IV is reached and a first significant topological change takes place: a $\mathrm{V}(\mathrm{C} 4)$ monosynaptic basin is created taking its population mainly from the V(N,C4) disynaptic basin. Along this domain the population of the newly created monosynaptic $\mathrm{V}(\mathrm{C} 4)$ basin grows until reaching 0.4 electrons, while the population of the $\mathrm{V}(\mathrm{N}, \mathrm{C} 4)$ basin diminishes by 0.33 electrons. Therefore, a curly arrow reporting the electron flow along SSD-IV can be depicted, in which the classical Lewis structures are implicitly recovered (see Scheme 2). 


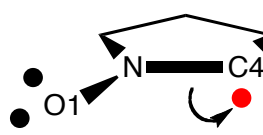<smiles></smiles>

SSD-IV

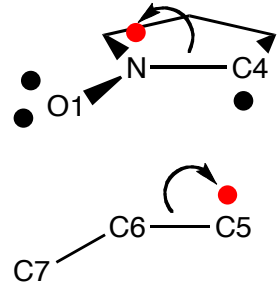

SSD-V

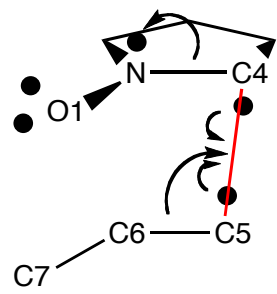

SSD-VI

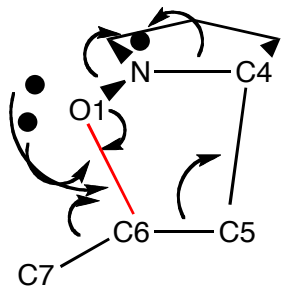

SSD-VII

Scheme 2. Flow of the electrons among the different basins for the indicated SSDs along the ortho/endo path. Heavy dots represent monosynaptic basins, continuous lines represent disynaptic basins, and the main core basins are indicated by the atomic symbol with the atom numbering. The basins that appear are depicted in red.

The population of the $\mathrm{V}(\mathrm{C} 4)$ monosynaptic basin keeps slightly growing along SSD-V. However, the main topological changes occurring in SSD-V are the appearances of the monosynaptic $\mathrm{V}(\mathrm{N})$ and $\mathrm{V}(\mathrm{C} 5)$ basins that take their populations mainly from the $\mathrm{V}(\mathrm{N}, \mathrm{C} 4)$ and $\mathrm{V}(\mathrm{C} 5, \mathrm{C} 6)$ basins: $\mathrm{V}(\mathrm{N})$ grows to 1.27 electrons, $\mathrm{V}(\mathrm{C} 5)$ to 0,41, while $\mathrm{V}(\mathrm{N}, \mathrm{C} 4)$ and $\mathrm{V}(\mathrm{C} 5, \mathrm{C} 6)$ lose 1.21 and 0.44 electrons, respectively. Accordingly, two curly arrows for SSD-V are depicted in Scheme 2.

When SSD-VI is reached, the distance between $\mathrm{C} 4$ and $\mathrm{C} 5$ has been reduced and the system is ready to experience the first of the two most significant topological changes: the two monosynaptic basins on $\mathrm{C} 4$ and $\mathrm{C} 5$ have been populated and they are ready to merge to each other, thus allowing the creation of the $\mathrm{V}(\mathrm{C} 4, \mathrm{C} 5)$ disynaptic basin accounting for the $\mathrm{C} 4-\mathrm{C} 5$ bond. To achieve this goal, a population transfer takes place to the new $\mathrm{V}(\mathrm{C} 4, \mathrm{C} 5)$ disynaptic basin from the $\mathrm{V}(\mathrm{C} 4)$ and $\mathrm{V}(\mathrm{C} 5)$ basins, which disappear with 0.62 and 0.41 electrons, respectively, and from $\mathrm{V}(\mathrm{C} 5, \mathrm{C} 6)$, which loses 0.15 electrons. At the end of SSD-VI, the $\mathrm{V}(\mathrm{C} 4, \mathrm{C} 5)$ disynaptic basin has acquired a population of 1.29 electrons. On the other hand, as can be seen in Figure 4 and also in Scheme 2, the population transfer from $\mathrm{V}(\mathrm{N}, \mathrm{C} 4)$ to $\mathrm{V}(\mathrm{N})$ continues along this domain, increasing the population of the monosynaptic basin by another 0.26 electrons, so as to achieve a total population of 1.53 electrons, while $\mathrm{V}(\mathrm{N}, \mathrm{C} 4)$ has a population of only 2.19 electrons at the end of SSD-VI, almost half the value found at the beginning of the whole process between $\mathrm{N}$ and $\mathrm{C} 4$ atoms (3.77 electrons).

The last SSD is characterized by the second most significant topological change: the appearance of the $\mathrm{V}(\mathrm{O} 1, \mathrm{C} 6)$ disynaptic basin accounting for the O1-C6 bond 
formation. The population of the new basin is very low at the beginning of the domain (only 0.14 electrons) but grows as the reaction continues to reach a final value of 1.23 electrons. These electrons come from several places: the two $V(\mathrm{O} 1)$ and $V^{\prime}(\mathrm{O} 1)$ monosynaptic basins contribute with 0.32 electrons each, the $\mathrm{V}(\mathrm{N}, \mathrm{O} 1)$ disynaptic basin with about 0.2 electrons, and even the $\mathrm{V}(\mathrm{C} 6, \mathrm{C} 7)$ disynaptic basin, which was slightly increasing its population until the end of SSD-VI, loses 0.25 electrons along SSD-VII. Apart from these flows, the population of $\mathrm{V}(\mathrm{N})$ keeps growing along SSD-VII with another 0.82 electrons, which come partly from the $\mathrm{V}(\mathrm{N}, \mathrm{C} 4)$ basin $(0.37$ electrons), partly from the $\mathrm{V}(\mathrm{N}, \mathrm{O} 1)$ basin (about 0.1 electrons), or even partly from the $\mathrm{V}(\mathrm{N}, \mathrm{C} 1)$ basin (not shown in Figure 4), which loses 0.2 electrons. Additionally, the electron flow between $\mathrm{V}(\mathrm{C} 5, \mathrm{C} 6)$ and $\mathrm{V}(\mathrm{C} 4, \mathrm{C} 5)$ continues, with about 0.6 electrons being transferred.

It is interesting to see that, although the topological changes between different SSDs take place in a very narrow range along the IRC, as stated above, the electron flows extend much more. In fact, along SSD-VII there is a wide range in which the basin populations change very much while maintaining the topological description of the system. Therefore, from the point of view of the electron flows, the process does not end with the last turning point between SSD-VI and SSD-VII, because large changes in the basin populations can be found along SSD-VII. Looking at Figure 4, it can be said that the electron flows began more or less at the second turning point found (at a value for the IRC of $-1.77 \mathrm{amu}^{1 / 2} \cdot \mathrm{bohr}$ ) and ended at a value of around $5 \mathrm{amu}^{1 / 2} \cdot \mathrm{bohr}$. This range represents almost $35 \%$ of the whole IRC. In addition, it can also be said that the main electron flows take place in a late stage of the reaction, from shortly before the TS until much later.

The description of the electron flows along the chemical process is fairly independent with respect to the theoretical level used: the same description offered above is repeated when the B3LYP level is used instead, with small non-significant variations in the amount of the particular population interchanges.

In a recent work, Domingo et al reported a BET study of the [3+2] cycloaddition between an acyclic nitrone (C-phenyl-N-methyl-nitrone) and acrolein, to render simple isoxazolidines $^{83}$, at the MPWB1K/6-31G(d) level. Although we study rather different systems (two cyclic nitrones reacting with ethyl acrylate to render bicyclic isoxazolidines), it is worth making a comparison with their results. For the ortho/endo regioisomeric path they found eight "phases", instead of seven SSDs. In their first turning point between phase I and phase II, the merging of the two $\mathrm{V}(\mathrm{C} 5, \mathrm{C} 6)$ disynaptic 
basins into one takes place, together with the appearance of the monosynaptic basins $\mathrm{V}(\mathrm{N})$ and $\mathrm{V}(\mathrm{C} 4)$. In the next turning point they report the $\mathrm{V}(\mathrm{C} 5)$ monosynaptic basin appearance. Thereafter the $\mathrm{V}(\mathrm{C} 4, \mathrm{C} 5)$ is formed by disappearing both monosynaptic basins $\mathrm{V}(\mathrm{C} 4)$ and $\mathrm{V}(\mathrm{C} 5)$. In phase $\mathrm{V}$ they detect the appearance of a transient $\mathrm{V}(\mathrm{C} 6)$ monosynaptic basin, which has got always a very low population. After that they distinguish between phase $\mathrm{V}$ and phase VI on the basis of variations in the populations of some basins, although the topological description of the system is the same for both phases. In their phase VII the transient V(C6) monosynaptic basin disappears, and hence phase VII has the same topology than their previous phase IV. Finally, the V(O1C6) disynaptic basin appears at phase VIII. It must be said that the work of Domingo et $a l$ is rather different from ours: first, they divide the reaction into "phases" instead of SSDs, and differentiate two consecutive "phases" with the same ELF topology, that from our point of view constitute a unique SSD. Second, they do not report the population evolution of the basins as a function of the IRC coordinate, but as a function of a regular spacing of phases, and therefore it is difficult in their work to appreciate the synchronicity/asynchronicity of the topological changes. And third, they do not recover curly arrows from their results. These aspects, together with the rather distinct systems studied, make a sound difference between both works. All and all, while keeping in mind these differences, both works agree in the main trends: the appearance of monosynaptic basins on $\mathrm{C} 4, \mathrm{~N}$ and $\mathrm{C} 5$, whatever the order, precedes the $\mathrm{C} 4-\mathrm{C} 5$ bond formation, and the finally the O1-C6 bond forms.

\section{BET study of the meta/endo regioisomeric pathway for nitrone 1}

The BET study of the meta/endo regioisomeric pathway at the M06-2X/6$311++\mathrm{G}^{* *}$ level indicates that the process takes place along six SSDs. The positions of the ELF basins for representative points belonging to each of the SSDs are shown in Figure 5, together with the position of the ELF basins for the corresponding isoxazolidine product. 


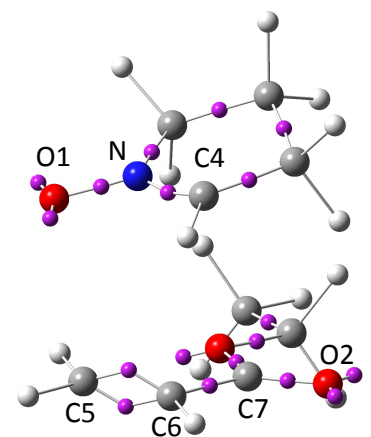

SSD-I

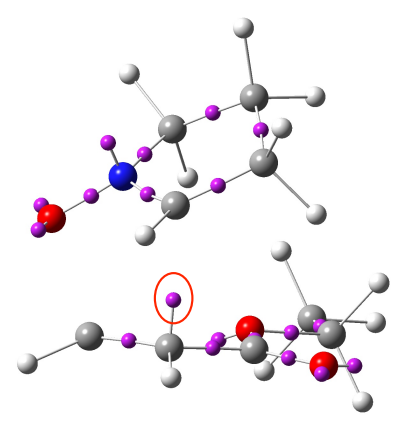

SSD-IV

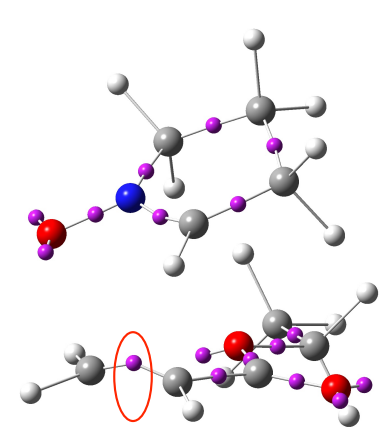

SSD-II

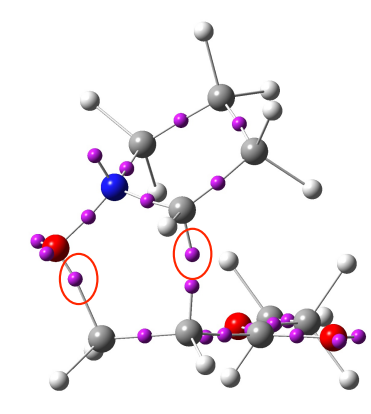

SSD-V

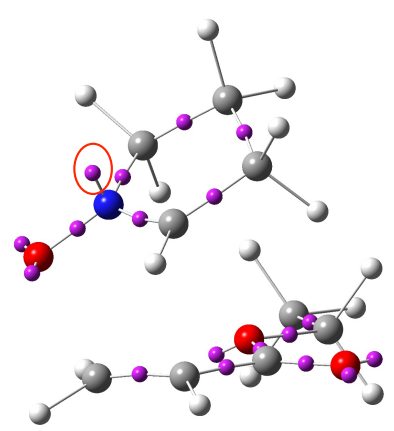

SSD-III

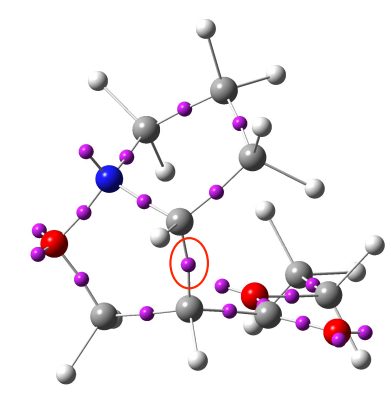

Product (SSD-VI)

Figure 5. ELF attractor positions for selected points that are representative of each of the SSDs found along the IRC associated with TS1men, as well as for the reaction product. The numbering used for some atoms is shown, and a red ellipse has been used to highlight the topological changes encountered.

At SSD-I only a disynaptic V(N,C4) basin is found, while the rest of the system is described with the same topology already found in the previous chapter. In this case both theoretical levels describe the same topology (see Figure 4S in Supporting information). The first topological change detected is the merging of the two disynaptic basins between $\mathrm{C} 5$ and $\mathrm{C} 6$ into a single $\mathrm{V}(\mathrm{C} 5, \mathrm{C} 6)$ basin. After that, the first monosynaptic basin to appear is $\mathrm{V}(\mathrm{N})$ (in SSD-III), then $\mathrm{V}(\mathrm{C} 6)$ in SSD-IV, and finally $\mathrm{V}(\mathrm{C} 4)$ in SSD-V. It should be noted that the monosynaptic basin on the $\mathrm{C}$ atom at the acrylate moiety now appears on the secondary $\mathrm{C} 6$ atom and not on the primary $\mathrm{C} 5$ atom, because the $\mathrm{C}-\mathrm{C}$ bond is going to be formed between $\mathrm{C} 4$ and $\mathrm{C} 6$. As described before, the $\mathrm{C}-\mathrm{C}$ bond formation takes place with the appearance of a monosynaptic basin onto each of the $\mathrm{C}$ atoms, which merge to form a disynaptic $\mathrm{V}(\mathrm{C}, \mathrm{C})$ basin, while the $\mathrm{C}-\mathrm{O}$ bond formation takes place by the sudden appearance of a $\mathrm{V}(\mathrm{O}, \mathrm{C})$ disynaptic. Unlike the preceding case, this time the $\mathrm{V}(\mathrm{O} 1, \mathrm{C} 5)$ disynaptic basin appears first, in SSD-V, coinciding with the appearance of $\mathrm{V}(\mathrm{C} 4)$, and the last topological change detected is the $\mathrm{C}-\mathrm{C}$ bond formation via the merging of $\mathrm{V}(\mathrm{C} 4)$ and $\mathrm{V}(\mathrm{C} 6)$ into a 
$\mathrm{V}(\mathrm{C} 4, \mathrm{C} 6)$ disynaptic basin, in SSD-VI. At the B3LYP level, the appearance of the $\mathrm{V}(\mathrm{O} 1, \mathrm{C} 5)$ disynaptic basin does not coincide with the appearance of the $\mathrm{V}(\mathrm{C} 4)$ monosynaptic basin, and therefore seven SSDs are needed to describe the whole process. This is the only difference between the topological description offered by the two theoretical levels, and the main trends have also been found.

The population evolution along the IRC for the most representative basins is depicted in Figure 6. In this case the topological changes appear sparser than in the preceding case. Therefore, the process is not so synchronous: by using equations (1) to (3) the absolute synchronicity has been calculated to be $\mathrm{Sy}^{\mathrm{abs}}=0.79$, i.e., $79 \%$ of the maximum synchronicity. The IRC extends this time from -7.46 to 8.71 , and therefore the TS is located at $46.2 \%$ of the IRC, thus having a more reactant-like character. At the B3LYP level (see Figure 5S in supporting information), the absolute synchronicity is somewhat lower $\left(\mathrm{Sy}^{\mathrm{abs}}=0.76\right)$ due to the non-coincidence in the appearance of the monosynaptic $\mathrm{V}(\mathrm{C} 4)$ basin and the disynaptic $\mathrm{V}(\mathrm{O} 1, \mathrm{C} 5)$ basin. Moreover, at the B3LYP level the TS has been found later along the IRC, being located at $56.3 \%$ of it.

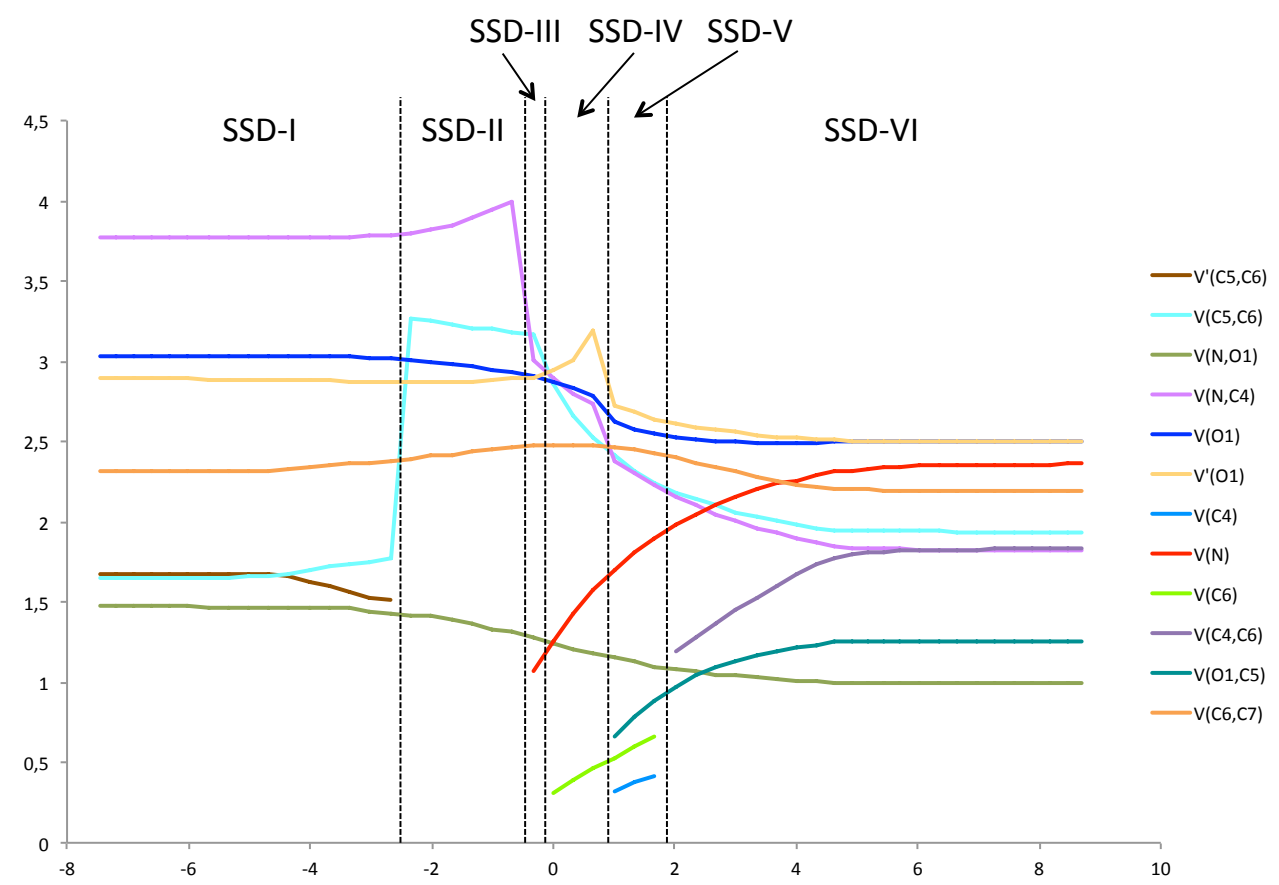

Figure 6. Population (in electrons) evolution of selected basins along the IRC associated with TS1men as a function of the IRC coordinate (in $\mathrm{amu}^{1 / 2} \cdot \mathrm{bohr}$ ). The separate reactants are located on the left, while the product of the cycloaddition is on the right. Dashed lines indicate the frontiers between the SSDs found. 
As can be seen in Figure 6, nothing seems to happen along SSD-I and, as before, only by the end of the domain slight changes in the $\mathrm{V}^{\prime}(\mathrm{C} 5, \mathrm{C} 6)$ and $\mathrm{V}(\mathrm{C} 5, \mathrm{C} 6)$ basin populations are detected. This basins merge at the turning point between SSD-I and SSD-II to render a single basin with a population that is equal to the sum of the populations of the separate basins. In SSD-III the V(N) monosynaptic basin appears, taking its population from the $\mathrm{V}(\mathrm{N}, \mathrm{C} 4)$ disynaptic basin. The $\mathrm{V}(\mathrm{N})$ population grows until $1.07 \mathrm{e}$, and the $\mathrm{V}(\mathrm{N}, \mathrm{C} 4)$ population decreases by 1 e along SSD-III (see Scheme $3)$.

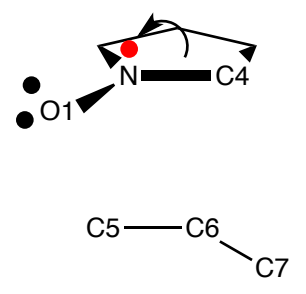

SSD-III

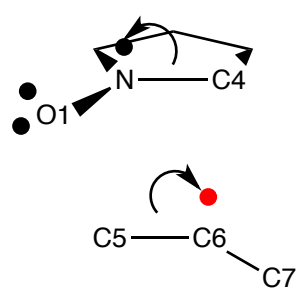

SSD-IV

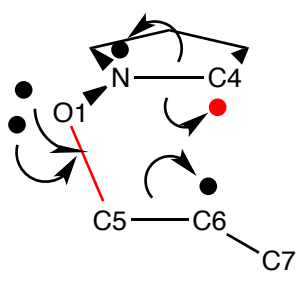

SSD-V

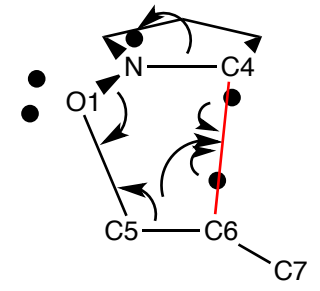

SSD-VI

Scheme 3. Flow of the electrons among the different basins for the indicated SSDs along the meta/endo path. Heavy dots represent monosynaptic basins, continuous lines represent disynaptic basins, and the main core basins are indicated by the atomic symbol with the atom numbering. The basins that appear are depicted in red.

A second monosynaptic basin appears on C6 in SSD-IV. Along this domain, the population of $\mathrm{V}(\mathrm{C} 6)$ increases by up to $0.46 \mathrm{e}$, which are taken from the $\mathrm{V}(\mathrm{C} 5, \mathrm{C} 6)$ disynaptic basin. In addition, the $\mathrm{V}(\mathrm{N})$ population keeps growing, mainly taking electrons from $\mathrm{V}(\mathrm{N}, \mathrm{C} 4)$. The third monosynaptic basin appears on C4 in SSD-V. Its population comes from the disynaptic $\mathrm{V}(\mathrm{N}, \mathrm{C} 4)$ basin. But this is not the only transfer that can be detected along SSD-V: the $\mathrm{V}(\mathrm{N})$ population increases by $0.32 \mathrm{e}$, which are also taken from the $\mathrm{V}(\mathrm{N}, \mathrm{C} 4)$ basin. In addition, the $\mathrm{V}(\mathrm{C} 6)$ monosynaptic basin slightly increases its population by $0.2 \mathrm{e}$, which come from the $\mathrm{V}(\mathrm{C} 5, \mathrm{C} 6)$ basin. Also in SSD-V the first of the bonds is formed: the $\mathrm{V}(\mathrm{O} 1, \mathrm{C} 5)$ disynaptic basin appears and its population (0.89 e) is withdrawn almost completely from $\mathrm{V}^{\prime}(\mathrm{O} 1)$ and $\mathrm{V}(\mathrm{O} 1)$. Therefore, five curly arrows are depicted in SSD-V in Scheme 3.

The last of the domains, SSD-VI, exhibits a huge reorganization of the electrons that flow from $\mathrm{V}(\mathrm{N}, \mathrm{C} 4)$ to $\mathrm{V}(\mathrm{N})$; from $\mathrm{V}(\mathrm{C} 4), \mathrm{V}(\mathrm{C} 6)$, and $\mathrm{V}(\mathrm{C} 5, \mathrm{C} 6)$ to the newly formed $\mathrm{V}(\mathrm{C} 4, \mathrm{C} 6)$; and from $\mathrm{V}(\mathrm{N}, \mathrm{O} 1)$ and $\mathrm{V}(\mathrm{C} 5, \mathrm{C} 6)$ to the $\mathrm{V}(\mathrm{O} 1, \mathrm{C} 5)$ basin. As can be 
seen in Figure 6, the significant changes in the basin population take place to a larger or lesser extent from the first turning point $\left(\mathrm{s}=-2.51 \mathrm{amu}^{1 / 2} \cdot \mathrm{bohr}\right)$ to a well-advanced point of the SSD-VI, at $\mathrm{s} \cong 4.6 \mathrm{amu}^{1 / 2}$ bohr. This range represents the $44 \%$ of the whole IRC and, as happened before, the range at which the main electron flows take place extends from shortly before to well after the TS.

In our study we have found only six (or seven, depending on the theoretical approach) SSDs instead of the eight phases described by Domingo et $a l^{83}$. In their paper, the monosynaptic basins appear in a different order: first appears $\mathrm{V}(\mathrm{C} 6)$, followed by $\mathrm{V}(\mathrm{N})$, and finally $\mathrm{V}(\mathrm{C} 4)$. They also detect a phase in which a transient additional monosynaptic basin appears on $\mathrm{O} 1$ before the formation of the disynaptic $\mathrm{V}(\mathrm{O} 1, \mathrm{C} 5)$ basin. The formation of the $\mathrm{V}(\mathrm{C} 4, \mathrm{C} 6)$ basin closes the process. As before, despite the differences between our study and Domingo's, the main trends are the same: the appearance of the three monosynaptic basins on N, C6, and C5, formation of the O1-C5 bond first, and final formation of the $\mathrm{V}(\mathrm{C} 4, \mathrm{C} 6)$ disynaptic basin.

\section{BET study of the ortho- and meta/exo regioisomeric pathways for nitrone 1}

At variance with the Domingo's work ${ }^{83}$, we have also explored the exo pathways in search of differences with respect to the topological description of the endo processes detailed above, and the results obtained are reported in Table 4.

The ortho/exo pathway can be described from the topological point of view also as a series of seven SSDs. There is a difference with respect to the results for the ortho/endo path, namely, the monosynaptic basin $\mathrm{V}(\mathrm{N})$ appears before the appearance of the $\mathrm{V}(\mathrm{C} 4)$ basin. The absolute synchronicity is found to be 0.91 , which is also very high and slightly larger than the absolute synchronicity for the ortho/endo case. Therefore, with the proviso of the earlier appearance of the $\mathrm{V}(\mathrm{N})$ basin, the topological description is equivalent for both ortho paths. The TS is found in this case at a fairly late position along the IRC: at $63.1 \%$. At the B3LYP level six domains have been found instead of seven. This difference arises from the turning point between SSD-I and SSDII, which accounts for the merging of the two disynaptic basins $\mathrm{V}(\mathrm{C} 5, \mathrm{C} 6)$ and $\mathrm{V}$ '(C5,C6), but also for the appearance of the $\mathrm{V}(\mathrm{C} 4)$ monosynaptic basin, that precedes the $\mathrm{V}(\mathrm{N})$ appearance. The $\mathrm{V}(\mathrm{C} 4, \mathrm{C} 5)$ basin formation takes also place first and the $\mathrm{V}(\mathrm{C} 6, \mathrm{O} 1)$ basin appearance closes the process. As for the synchronicity the calculated value is $\mathrm{Sy}^{\mathrm{abs}}=0.88$, a value that is rather similar to the one found for the endo process 
(0.85). This again describes the topological changes as very synchronous and in a central region along the IRC (the TS is found this time at $53.8 \%$ of the IRC). The flow of electrons described before can also be applied in the ortho/exo case.

The meta/exo pathway can be described as a series of seven SSDs, like the meta/endo case. The topological changes take place in the same order as before. As for the synchronicity of the changes between the different domains, the calculated values are $\mathrm{Sy}^{\mathrm{abs}}=0.89$ at the M06-2X level and 0.80 at the B3LYP, slightly higher values than the ones found for the meta/endo process, and slightly less synchronous than the corresponding ortho case. The TS is found this time at $46.6 \%$ of the IRC $(56.9 \%$ at the B3LYP), more or less as in the endo cases. The flow of electrons described earlier can also be applied here.

BET study of the pathways for nitrone 2

For the sake of completeness, we have also explored the four pathways for the reaction between nitrone 2 and ethyl acrylate, only at the B3LYP/6-31G(d) level. The results obtained indicate that the topological description for each of the pathways is roughly the same with independence of the nitrone. Thus, the ortho/endo regioisomeric pathway can also be described along seven structural stability domains accounting for the same changes in the topology as described for nitrone 1, and in the same order. The absolute synchronicity obtained is $\mathrm{Sy}^{\mathrm{abs}}=0.87$, very close to the value obtained for nitrone 1 at the same theoretical level (0.85). Moreover, the TS is also located roughly midway along the IRC, at $52.1 \%$.

A small difference can be detected for the meta/endo pathway: in the nitrone $\mathbf{2}$ case we have found six SSDs instead of seven, because the appearance of the monosynaptic basins $\mathrm{V}(\mathrm{N})$ and $\mathrm{V}(\mathrm{C} 6)$ takes place at the same time instead of consecutively. The $\mathrm{Sy}^{\mathrm{abs}}$ value is 0.73 for nitrone 2 . We have also found that the meta/endo pathway is less synchronous than the ortho one. The TS is now located at $51.4 \%$ of the IRC, $5 \%$ more centered than in the case of nitrone 1.

With respect to the exo pathways, the ortho/exo path shows that the process can be described with six SSDs in both cases: for nitrone 1 the merging of the disynaptic basins between C5 and C6 takes place concomitantly with the appearance of the monosynaptic basin on $\mathrm{C} 4$, while for nitrone 2 the appearance of the monosynaptic basins on $\mathrm{C} 4$ and on $\mathrm{N}$ takes place at the same time. This fact is reflected in the Sy ${ }^{\text {abs }}$ 
values, which are close to $90 \%$ : 0.88 for nitrone $\mathbf{1}$, and 0.92 for nitrone 2 . The TS is located slightly displaced toward products for the case of nitrone $\mathbf{1}$, while it is found displaced toward reactants for the case of nitrone 2.

Finally, the meta/exo pathway is also described by seven SSDs taking place in the same order as in the case of nitrone 1. The absolute synchronicity is calculated to be 0.82 , very close to the preceding case $(0.80)$, the TS being found at $55.2 \%$ of the IRC, $1.7 \%$ more centered than in the case of nitrone 1.

In spite of the small differences found, the main conclusions from the study of the nitrone 1 case are also reached by studying nitrone 2: the processes along the ortho pathways are more synchronous than the corresponding processes through the meta paths, the monosynaptic basins appear in the early stages, and the $\mathrm{C}-\mathrm{C}$ bond forms prior to the formation of the $\mathrm{C}-\mathrm{O}$ bond along the ortho paths. In the meta paths, however, the $\mathrm{C}-\mathrm{O}$ bond is formed prior to the $\mathrm{C}-\mathrm{C}$.

\section{Final remark}

Finally, and in accordance with the above findings, the reaction mechanism can be rationalized by using the classical curly arrows for electronic motions accompanying the breaking of chemical bonds, the forming of new chemical bonds or the rearrangements of electron pairs, together with the associated transitions from single to double bonds or vice-versa (see Scheme 4), thereby retrieving the classical Lewis representation. Using this type of analysis, we can conclude that this reaction can be dissected into four consecutive stages: the first stage yields the reorganization of the valence molecular shells of $\mathrm{N}$ and $\mathrm{C} 4$ atoms, in which the $\mathrm{N}-\mathrm{C} 4$ double bond lowers its population to become a single bond. The second part of the reaction path can be viewed as a reorganization of the valence molecular shells of $\mathrm{C} 5$ and $\mathrm{C} 6$ atoms, in which the formal double $\mathrm{C} 5$-C6 bond also lowers its population to form a single bond. In the third and fourth stages along the ortho pathway, the $\mathrm{C} 4-\mathrm{C} 5$ and $\mathrm{O} 1-\mathrm{C} 6$ bonds are formed, respectively, while along the meta channel, the O1-C5 bond is formed before the $\mathrm{C} 4-\mathrm{C} 6$ bond. This picture is confirmed by the sequence of the catastrophes reported in the BET studies and by the evolution of the basin populations displayed in the reported figures. Therefore, this type of 1,3-DC reaction can be analyzed from the electron density rearrangements provided by BET, in which the bond breaking/forming processes take place in a consecutive fashion, discarding the concerted nature of this kind of 1,3-DC 
processes, and highlighting the limitations of the use of geometry, the bond order, and the charge transfer in the transition structure for classifying and quantifying the (a)synchronicity.

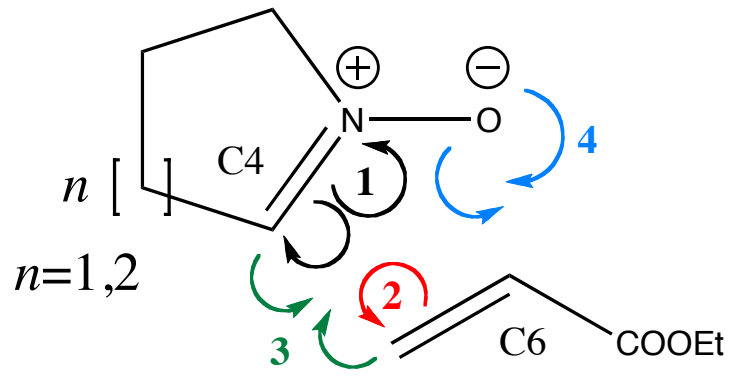

C5

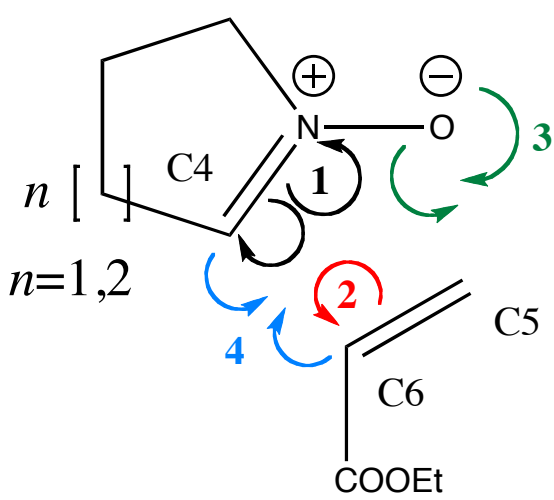

Meta Channel

Ortho Channel

Scheme 4. Summary of the electronic motions, described by curly arrows, accompanying the breaking and forming of chemical bonds along the reaction progress, according to the classical Lewis representation.

\section{Conclusions}

By using BET, which combines the topological analysis of ELF and Thom's catastrophe theory, we have obtained a great deal of fundamental knowledge, which provides a better understanding of how the flow of electron density along the reaction progress determines chemical reactivity. It represents a considerable advantage over orbital or conceptual density functional based theories.

It has become common to reference 1,3-dipolar cycloaddition (1,3-DC) when describing the chemical reaction between a 1,3-dipole and a dipolarophile. Here, a BET study on the formal 1,3-DC reaction of two cyclic nitrones, pyrroline-1-oxide (1) and 2,3,4,5 tetrahydropyridine-1-oxide (2), with ethyl acrylate, has been carried out as a case study.

The main conclusions from the present work can be summarized as follows: 
i) Four reactive channels have been found to be possible for these 1,3-DC processes, depending on the relative orientation of the two reactants: the ortho or meta approaches with endo or exo orientations. Among them, and depending on the theoretical level used, the endo pathways are calculated to be, in general, slightly favorable with respect the exo channels, although the energy differences are small and the four channels will compete to some extent.

ii) We have shown the limited influence of the ring size and theoretical level on the description of the electron flowing along the studied reaction paths.

iii) In the ortho/endo case the topological changes include the appearance of $\mathrm{V}(\mathrm{C} 4), \mathrm{V}(\mathrm{N})$, and $\mathrm{V}(\mathrm{C} 5)$, the appearance of the $\mathrm{V}(\mathrm{C} 4, \mathrm{C} 5)$ disynaptic basin concomitantly with the disappearance of the $\mathrm{V}(\mathrm{C} 4)$ and $\mathrm{V}(\mathrm{C} 5)$ monosynaptic basins, and the final $\mathrm{V}(\mathrm{O} 1, \mathrm{C} 6)$ bond formation. For the meta pathways the order of appearance of the monosynaptic basins differs slightly (first V(N), then V(C6), and V(C4)), and the formation of the $\mathrm{V}(\mathrm{O} 1, \mathrm{C} 5)$ disynaptic basin takes place before the formation of the $\mathrm{V}(\mathrm{C} 4, \mathrm{C} 6)$ basin.

iv) We have defined a new parameter based on the BET study that accounts for the synchronicity in which the topological changes take place along the IRC. The synchronicity values for the ortho/endo channel are slightly lower than for the ortho/exo pathway for both nitrones. Moreover, the meta channels show absolute synchronicities that are lower than those of the corresponding ortho paths. These results show the relevance of BET analysis for classifying and quantifying the (a)synchronicity of the 1,3-DC reaction mechanisms.

v) The topological changes take place via consecutive steps, and the electronic rearrangement extends along almost half the IRC, ruling out the concerted character of this kind of 1,3-DC processes.

vi) In all cases it has been found that from the appearance of the first monosynaptic basin, the system experiences a huge electron transfer process, in which the creation and population of the $\mathrm{V}(\mathrm{N})$ monosynaptic basin concomitantly with the depopulation of the $\mathrm{V}(\mathrm{N}, \mathrm{C} 4)$ basin, can be considered as being responsible for the electron flow of the system along the reaction, together with the formation of the two new bonds.

vii) The BET results indicate that the reaction mechanisms can be represented by four consecutive stages, as follows: 1) the $\mathrm{N}-\mathrm{C} 4$ bond lowers its population losing its initial double bond character; 2) the double C5-C6 bond also depopulates in its 
transformation into a single bond. Along the ortho pathway the sequence is: 3) the C4-C5 bond-forming processes take place, and 4) the O1-C6 bond-forming process occurs, while an inverse order between 3) and 4) appears along the meta channel.

viii) The present BET analysis provides an alternative to drawing electron pushing arrows in Lewis structures, and using pictures of the electron transfers along the progress of chemical reactions.

The purpose of this article is to outline an approach that provides physical information on a quantitative level that complements and overcomes the interpretations based on traditional $\mathrm{MO}, \mathrm{VB}$, or $\mathrm{CDF}$ theories of reaction mechanisms. The ideas presented in this work comprise a new description of reaction mechanisms of 1,3 DC rearrangements that can be extended to the study of larger systems.

\section{Acknowledgments}

V. S. Safont, M. Oliva, and J. Andrés are grateful to Generalitat Valenciana for PrometeoII/2014/022 and ACOMP/2015/1202, to Universitat Jaume I for project UJIB2016-25, and to Ministerio de Economía y Competitividad (Spain) for project CTQ2015-65207-P. J. Andrés, V. S. Safont and M. Oliva are also grateful to Universitat Jaume I for project UJI-B2016-25. A. I. Adjieufack, I. M. Ndassa, I. Patouossa, and J. K. Mbadcam are grateful to the Ministry of Higher Education of the Republic of Cameroon for funding the project with a modernization research grant. The authors also thank the University of Yaoundé I and High Teacher Training College (Cameroon) for infrastructural facilities and the Servei d'Informàtica, Universitat Jaume I, for generous allocation of computer time.

\section{References}

1. K. Fukui, T. Yonezawa and H. Shingu, J. Chem. Phys., 1952, 20, 722-725.

2. R. B. Woodward and R. Hoffmann, Angew. Chem. Int. Ed., 1969, 8, 781-932.

3. G. N. Lewis, J. Am. Chem. Soc., 1916, 38, 762-785.

4. L. Pauling, J. Am. Chem. Soc., 1931, 53, 1367-1400.

5. $\quad$ L. Pauling, J. Am. Chem. Soc., 1931, 53, 3225-3237.

6. $\quad$ L. Pauling, J. Am. Chem. Soc., 1932, 54, 988-1003.

7. L. Pauling, The Nature of the Chemical Bond, Cornell University Press, Ithaca, 3rd edn., 1960.

8. S. Shaik and A. Shurki, Angew. Chem. Int. Ed., 1999, 38, 586-625.

9. A. Shurki, E. Derat, A. Barrozo and S. C. L. Kamerlin, Chem. Soc. Rev., 2015, 44, 1037-1052.

10. D. O'Hagan and D. Lloyd, Chemistry World, 2010, 7, 54-57.

11. R. B. Grossman, The art of writing reasonable organic reaction mechanisms, Springer-Verlag, New York, 2nd edn., 2003.

12. G. Knizia and J. E. M. N. Klein, Angew. Chem. Int. Ed., 2015, 54, 5518-5522. 
13. R. G. Parr and W. Yang, Density-Functional Theory of Atoms and Molecules, Oxford University Press, New York, 1989.

14. P. Geerlings, F. De Proft and W. Langenaeker, Chem. Rev., 2003, 103, 1793-1874.

15. P. K. Chattaraj, ed., Chemical Reactivity Theory: a Density Functional View, CRC Press, Boca Raton, FL, 2009.

16. S. Shahbazian and M. Zahedi, Foundations of Chemistry, 2006, 8, 37-52.

17. S. Shahbazian and M. Zahedi, Foundations of Chemistry, 2007, 9, 85-95.

18. J. Poater, M. Solà and F. M. Bickelhaupt, Chem. Eur. J., 2006, 12, 2902-2905.

19. P. Hohenberg and W. Kohn, Phys. Rev., 1964, 136, B864-B871.

20. R. F. W. Bader, Atoms in Molecules: A Quantum Theory, Clarendon Press, Oxford, New York, 1990.

R. F. W. Bader, T. T. Nguyen-Dang and Y. Tal, Reports on Progress in Physics, 1981, 44, 893948.

22. P. L. A. Popelier and É. A. G. Brémond, Int. J. Quantum Chem., 2009, 109, 2542-2553.

23. R. H. Abraham and C. D. Shaw, Dynamics: The Geometry of Behavior, Addison-Wesley, Redwood City, CA, 2nd edn., 1992.

24. X. Krokidis, S. Noury and B. Silvi, J. Phys. Chem. A, 1997, 101, 7277-7282.

25. A. D. Becke and K. E. Edgecombe, J. Chem. Phys., 1990, 92, 5397-5403.

26. B. Silvi and A. Savin, Nature, 1994, 371, 683-686.

27. R. Thom, Structural Stability and Morphogenesis, an Outline of a General Theory of Models, Addison-Wesley, Reading, Massachusets, 1975.

28. P. González-Navarrete, L. R. Domingo, J. Andrés, S. Berski and B. Silvi, J. Comput. Chem., 2012, 33, 2400-2411.

29. V. Polo and J. Andres, Journal of Computational Chemistry, 2005, 26, 1427-1437.

30. V. Polo, J. Andrés, R. Castillo, S. Berski and B. Silvi, Chem. Eur. J., 2004, 10, 5165-5172.

31. V. Polo, J. Andrés and B. Silvi, J. Comput. Chem., 2007, 28, 857-864.

32. V. S. Safont, P. González-Navarrete, M. Oliva and J. Andrés, Phys. Chem. Chem. Phys., 2015, 17, 32358-32374.

33. R. F. W. Bader, S. Johnson, T.-H. Tang and P. L. A. Popelier, J. Phys. Chem., 1996, 100, 1539815415.

34. F. Feixas, E. Matito, M. Duran, M. Solà and B. Silvi, J. Chem. Theor. Comput., 2010, 6, 27362742.

35. V. Polo, J. Andrés, S. Berski, L. R. Domingo and B. Silvi, Journal of Physical Chemistry A, 2008, 112, 7128-7136.

36. J. Andrés, P. González-Navarrete and V. S. Safont, International Journal of Quantum Chemistry, 2014, 114, 1239-1252.

37. J. Andrés, L. Gracia, P. Gonzalez-Navarrete and V. S. Safont, Computational and Theoretical Chemistry, 2015, 1053, 17-30.

38. N. Gillet, R. Chaudret, J. Contreras-García, W. Yang, B. Silvi and J.-P. Piquemal, J. Chem. Theor. Comput., 2012, 8, 3993-3997.

39. P. González-Navarrete, J. Andrés and S. Berski, J. Phys. Chem. Lett., 2012, 3, 2500-2505.

40. A. Padwa, 1,3-Dipolar cycloaddition chemistry, Wiley Interscience, New York, 1984.

41. H.-U. Reissig and R. Zimmer, Angew. Chem. Int. Ed., 2014, 53, 9708-9710.

42. H.-U. Reissig and R. Zimmer, Angew. Chem., 2014, 126, 9864-9866.

43. J. Adrio and J. C. Carretero, Chem. Commun., 2014, 50.

44. M. S. Singh, S. Chowdhury and S. Koley, Tetrahedron, 2016, 72, 1603-1644.

45. H. Erguven, D. C. Leitch, E. N. Keyzer and B. A. Arndtsen, Angew. Chem. Int. Ed., 2016.

46. B. Gold, M. R. Aronoff and R. T. Raines, J. Org. Chem., 2016, 81, 5998-6006.

47. R. Huisgen, Proc. Chem. Soc., 1961, October 1961, 357-369.

48. A. Barbosa and J. Monteiro, Theor. Chem. Acc., 2012, 131, 1297-1323.

49. B. Braida, C. Walter, B. Engels and P. Hiberty, J. Am. Chem. Soc., 2010, 132, 7631-7637.

50. Y. Lan, S. E. Wheeler and K. N. Houk, J. Chem. Theor. Comput., 2011, 7, 2104-2111.

51. A. de Cozar and F. P. Cossio, Phys. Chem. Chem. Phys., 2011, 13, 10858-10868.

52. L. R. Domingo and S. R. Emamian, Tetrahedron, 2014, 70, 1267-1273.

53. L. R. Domingo, M. J. Aurell and P. Pérez, Tetrahedron, 2014, 70, 4519-4525.

54. L. R. Domingo, M. J. Aurell and P. Pérez, Tetrahedron, 2015, 71, 1050-1057.

55. R. A. Firestone, J. Org. Chem., 1968, 33, 2285-2290.

56. R. Huisgen, J. Org. Chem., 1968, 33, 2291-2297.

57. S. López, M. Munk and K. N. Houk, J. Org. Chem., 2013, 78, 1576-1582.

58. D. H. Ess and K. N. Houk, J. Am. Chem. Soc., 2008, 130, 10187-10198. 
59. D. H. Ess and K. N. Houk, J. Am. Chem. Soc., 2007, 129, 10646-10647.

60. S. Xie, S. A. López, O. Ramström, M. Yan and K. N. Houk, J. Am. Chem. Soc., 2015, 137, 2958-2966.

61. B. Engels and M. Christl, Angew. Chem. Int. Ed., 2009, 48, 7968-7970.

62. G. L. Barnes and W. L. Hase, Nature Chem., 2009, 1, 103-104.

63. L. Xu, C. E. Doubleday and K. N. Houk, J. Am. Chem. Soc., 2010, 132, 3029-3037.

64. L. Xu, C. E. Doubleday and K. N. Houk, Angew. Chem. Int. Ed., 2009, 48, 2746-2748.

65. A. Toro-Labbé, J. Phys. Chem. A, 1999, 103, 4398-4403.

66. P. Politzer, A. Toro-Labbé, S. Gutiérrez-Oliva and J. S. Murray, in Advances in Quantum Chemistry, Elsevier, 2012, vol. 64, ch. 6, pp. 189-209.

67. N. Villegas-Escobar, S. Vogt-Geisse, S. Gutiérrez-Oliva and A. Toro-Labbé, Theor. Chem. Acc., 2016, 135:191.

68. A. Guevara-García, P. W. Ayers, S. Jenkins, S. R. Kirk, E. Echegaray and A. Toro-Labbé, in Electronic Effects in Organic Chemistry, ed. B. Kirchner, Springer-Verlag, Berlin, 2014, vol. 351, ch. 3, pp. 103-124.

69. T. M. Sexton, M. Freindorf, E. Kraka and D. Cremer, J. Phys. Chem. A, 2016, 120, 8400-8418.

70. W. Benchouk and S. M. Mekelleche, J. Mol. Struct. THEOCHEM, 2008, 862, 1-6.

71. A. Hassner, ed., Sysnthesis of Heterocycles via Cycloadditions II, Springer, Berlin, 2008.

72. D. M. Patterson and J. A. Prescher, Curr. Op. Chem. Biol., 2015, 28, 141-149.

73. K. V. Gothelf and K. A. Jorgensen, Chem. Rev., 1998, 98, 863-910.

74. C. Chunsheng, L. Zhinian, S. Jinyan, L. Tao and Z. Baoyan, Front. Chem. China, 2006, 4, 427433.

75. R. Brindaban and N. D. Rajendra, Indian J. Chem. Sec B, 2013, 52B, 146-152.

76. S. Mukherjee, Raunak, A. Dhawan, Poonam, A. K. Prasad, C. E. Olsen, A. L. Cholli, W. Errington, H. G. Raj, A. C. Watterson and V. S. Parmar, Ind. J. Chem. Sec. B, 2004, 43B, 26702682.

77. H. Feuer, ed., Nitrile oxides, nitrones, and nitronates in organic synthesis: novel strategies in synthesis, John Wiley \& Sons, Inc., Hoboken NJ, 2008.

78. K. Marakchi, O. Kabbaj, N. Komiha, R. Jalal and M. Esseffar, J. Mol. Struct. THEOCHEM, 2003, 620, 271-281.

79. C. Di Valentin, M. Freccero, R. Gandolfi and A. Rastelli, J. Org. Chem., 2000, 65, 6112-6120.

80. W. Benchouk and S. M. Mekelleche, RSC Adv., 2015, 5, 22126-22134.

81. N. Acharjee, T. K. Das, A. Banerji, M. Banerjee and T. Prangé, J. Phys. Org. Chem., 2010, 23, 1187-1195.

82. K. Marakchi, R. Ghailane, O. K. Kabbaj and N. Komiha, J. Chem. Sci., 2014, 126, 283-292.

83. M. Ríos-Gutiérrez, P. Pérez and L. R. Domingo, RSC Adv., 2015, 5, 58464-58477.

84. R. A. Miranda-Quintana and P. W. Ayers, Theor. Chem. Acc., 2016, 135:172.

85. J. Andrés, S. Berski and B. Silvi, Chem. Commun., 2016, 52, 8183-8195.

86. Gaussian03, revision B.04. M. J. Frisch, G. W. Trucks, H. B. Schlegel, G. E. Scuseria, M. A. Robb, J. R. Cheeseman, J. Montgomery, J. A., T. Vreven, K. N. Kudin, J. C. Burant, J. M. Millam, S. S. Iyengar, J. Tomasi, V. Barone, B. Mennucci, M. Cossi, G. Scalmani, N. Rega, G. A. Petersson, H. Nakatsuji, M. Hada, M. Ehara, K. Toyota, R. Fukuda, J. Hasegawa, M. Ishida, T. Nakajima, Y. Honda, O. Kitao, H. Nakai, M. Klene, X. Li, J. E. Knox, H. P. Hratchian, J. B. Cross, V. Bakken, C. Adamo, J. Jaramillo, R. Gomperts, R. E. Stratmann, O. Yazyev, A. J. Austin, R. Cammi, C. Pomelli, J. W. Ochterski, P. Y. Ayala, K. Morokuma, G. A. Voth, P. Salvador, J. J. Dannenberg, V. G. Zakrzewski, S. Dapprich, A. D. Daniels, M. C. Strain, O. Farkas, D. K. Malick, A. D. Rabuck, K. Raghavachari, J. B. Foresman, J. V. Ortiz, Q. Cui, A. G. Baboul, S. Clifford, J. Cioslowski, B. B. Stefanov, G. Liu, A. Liashenko, P. Piskorz, I.

Komaromi, R. L. Martin, D. J. Fox, T. Keith, M. A. Al-Laham, C. Y. Peng, A. Nanayakkara, M. Challacombe, P. M. W. Gill, B. Johnson, W. Chen, M. W. Wong, C. Gonzalez and J. A. Pople, Gaussian, Inc. Wallingford CT, 2004.

87. Gaussian09, revision B.01. M. J. Frisch, G. W. Trucks, H. B. Schlegel, G. E. Scuseria, M. A. Robb, J. R. Cheeseman, G. Scalmani, V. Barone, B. Mennucci, G. A. Petersson, H. Nakatsuji, M. Caricato, X. Li, H. P. Hratchian, A. F. Izmaylov, J. Bloino, G. Zheng, J. L. Sonnenberg, M. Hada, M. Ehara, K. Toyota, R. Fukuda, J. Hasegawa, M. Ishida, T. Nakajima, Y. Honda, O. Kitao, H. Nakai, T. Vreven, J. A. Montgomery, Jr., J. E. Peralta, F. Ogliaro, M. Bearpark, J. J. Heyd, E. Brothers, K. N. Kudin, V. N. Staroverov, R. Kobayashi, J. Normand, K. Raghavachari, A. Rendell, J. C. Burant, S. S. Iyengar, J. Tomasi, M. Cossi, N. Rega, N. J. Millam, M. Klene, J. E. Knox, J. B. Cross, V. Bakken, C. Adamo, J. Jaramillo, R. Gomperts, R. E. Stratmann, O. Yazyev, A. J. Austin, R. Cammi, C. Pomelli, J. W. Ochterski, R. L. Martin, K. Morokuma, V. G. 
Zakrzewski, G. A. Voth, P. Salvador, J. J. Dannenberg, S. Dapprich, A. D. Daniels, Ö. Farkas, J. B. Foresman, J. V. Ortiz, J. Cioslowski and D. J. Fox, Gaussian, Inc. Wallingford CT, 2010.

88. K. Fukui, J. Phys. Chem., 1970, 74, 4161-4163.

89. C. González and H. B. Schlegel, J. Phys. Chem., 1990, 94, 5523-5527.

90. C. González and H. B. Schlegel, J. Chem. Phys., 1991, 95, 5853-5860.

91. J. P. Foster and F. Weinhold, J. Am. Chem. Soc., 1980, 102, 7211-7218.

92. S. Noury, X. Krokidis, F. Fuster and B. Silvi, Computers \& Chemistry, 1999, 23, 597-604.

93. GaussView, version 3, R. Dennington, T. Keith and J. Millam, Semichem Inc, Shawnee Mission, KS, 2009.

94. E. F. Pettersen, T. D. Goddard, C. C. Huang, G. S. Couch, D. M. Greenblatt, E. C. Meng and T. E. Ferrin, J. Comput. Chem., 2004, 25, 1605-1612.

95. J. Andrés, S. Berski, L. R. Domingo, V. Polo and B. Silvi, Curr. Org. Chem., 2011, 15, 35663575.

96. B. Silvi, in The chemical bond II. 100 years old and getting stronger., ed. M. P. Mingos, Springer International Publishing, Oxford, 2016, ch. 5, pp. 213-247.

97. M. Carda, R. Portolés, J. Murga, S. Uriel, J. A. Marco, L. R. Domingo, R. J. Zaragozá and H. Röper, J. Org. Chem., 2000, 65, 7000-7009. 